\title{
The Role of Reaction Affinity and Secondary Minerals in Regulating Chemical Weathering Rates at the Santa Cruz Soil Chronosequence, California
}

\author{
Kate Maher ${ }^{\mathrm{a}}$, Carl I. Steefel ${ }^{\mathrm{b}}$, Art F. White $^{\mathrm{c}}$ and Dave A. Stonestrom ${ }^{\mathrm{c}}$ \\ ${ }^{a}$ Department of Geological and Environmental Sciences, Stanford University, Stanford, CA 94305, USA \\ ${ }^{\mathrm{b}}$ Earth Sciences Division, Lawrence Berkeley National Laboratory, Berkeley, CA 94720, USA \\ ${ }^{c}$ U.S. Geological Survey, Menlo Park, CA 94025, USA
}




\begin{abstract}
:
In order to explore the reasons for the apparent discrepancy between laboratory and field weathering rates and to determine the extent to which weathering rates are controlled by the approach to thermodynamic equilibrium, secondary mineral precipitation and flow rates, a multicomponent reactive transport model (CrunchFlow) was used to interpret soil profile development and mineral precipitation and dissolution rates at the $226 \mathrm{ka}$ marine terrace chronosequence near Santa Cruz, CA. Aqueous compositions, fluid chemistry, transport, and mineral abundances are well characterized (White et al., 2008, GCA) and were used to constrain the reaction rates for the weathering and precipitating minerals in the reactive transport modeling. When primary mineral weathering rates are calculated with either of two experimentally determined rate constants, the nonlinear, parallel rate law formulation of Hellmann and Tisserand [2006] or the aluminum inhibition model proposed by Oelkers et al. [1994], modeling results are consistent with fieldscale observations when independently constrained clay precipitation rates are accounted for. Experimental and field rates, therefore, can be reconciled at the Santa Cruz site.
\end{abstract}

Observed maximum clay abundances in the argillic horizons occur at the depth and time where the reaction fronts of the primary minerals overlap. The modeling indicates that the argillic horizon at Santa Cruz can be explained almost entirely by weathering of primary minerals and in situ clay precipitation accompanied by undersaturation of kaolinite at the top of the profile. The rate constant for kaolinite precipitation was also determined based on model simulations of mineral abundances and dissolved $\mathrm{Al}, \mathrm{SiO}_{2}(\mathrm{aq})$ and $\mathrm{pH}$ in pore waters. Changes in the rate of kaolinite precipitation or the flow rate do not affect the gradient of the primary mineral weathering profiles, but instead control the rate of propagation of the primary mineral weathering fronts and thus total mass removed from the weathering profile. Our analysis suggests that secondary clay precipitation is as important as aqueous transport in governing the amount of dissolution that occurs within a profile because clay minerals exert a strong control over the reaction affinity of the dissolving primary minerals. The modeling also indicates that the weathering advance rate and the total mass of mineral dissolved is controlled by the thermodynamic saturation of the primary dissolving phases plagioclase and K-feldspar, as is evident from the difference in propagation rates of the reaction fronts for the two minerals despite their very similar kinetic rate laws.

Hellmann R. and Tisserand D. (2006) Dissolution kinetics as a function of the Gibbs free energy of reaction: An experimental study based on albite feldspar. Geochimica Et Cosmochimica Acta 70(2), 364-383.

Oelkers E. H., Schott J., and Devidal J. L. (1994) The effect of aluminum, pH, and chemical affinity on the rates of aluminosilicate dissolution reactions. Geochimica Et Cosmochimica Acta 58(9), 2011-2024.

White A. F., Schulz M. S., Vivit D. V., Blum A., Stonestrom D. A., and Anderson S. P. (2008) Chemical Weathering of a Marine Terrace Chronosequence, Santa Cruz, California I: Interpreting the Long-Term Controls on Chemical Weathering based on Spatial and Temporal Element and Mineral Distributions Geochimica Et Cosmochimica Acta 72(1), 36-68. 


\section{INTRODUCTION}

Chemical weathering rates are affected by several distinct processes that are in practice difficult to separate in natural systems. These processes include advective and diffusive transport, secondary mineral precipitation, and the solubility and intrinsic kinetics of individual minerals. These processes are linked by their individual effect on the overall saturation state of the dissolving mineral. Recent field observations and laboratory-based studies have suggested that secondary mineral precipitation can regulate the dissolution rates of primary minerals (Alekseyev et al., 1997; Zhu et al., 2004; Maher et al., 2006b) and partly control elemental fluxes (Michalopoulos and Aller, 1995; Stefansson and Gislason, 2001). Such precipitation should moderate chemical weathering rates (defined here as the dissolution of primary minerals) by 1) controlling the saturation state of primary minerals in natural waters (Alekseyev et al., 1997; Maher et al., 2006b), 2) potentially obscuring or restricting the reactive surface area of primary minerals (Kohler et al., 2003; White and Brantley, 2003), and 3) and reducing the permeability of the porous media and creating preferential flow (Perillo et al., 1999). However, the extent to which secondary mineral precipitation controls primary weathering has not been explicitly evaluated. This relationship is difficult to predict in natural systems because reliable pore water chemical analyses, especially for such elements as aluminum, and quantitative determination of secondary mineral abundances are often not available. In many environments, it is also difficult to determine the exact composition of precipitating phases, and as a consequence, the thermodynamic properties of the precipitating minerals. The interpretation of secondary mineral abundances in many soil profiles is also complicated by poorly characterized initial abundances and translocation and flocculation of primary clay minerals, processes that obscure the extent of in situ precipitation.

Understanding the relationship between primary silicate weathering and secondary clay formation is important in natural systems such as soils and sediments because clay formation can affect the biogeochemistry by controlling nutrient availability, elemental fluxes, and the quality and quantity of transmitted water (Casey et al., 1993; Hopkins and Franzen, 2003). Lithogenic ally-derived nutrients become irreversibly depleted from soils as the transformation of primary minerals to secondary minerals proceeds because 1:1 layer clays such as kaolinite have both a low cation exchange capacity and are depleted in structural cations. In sedimentary environments, the process of "reverse weathering" or the formation of 2:1 clays is proposed to impact elemental fluxes by sequestering cations and potentially releasing $\mathrm{CO}_{2}$ (Michalopoulos and Aller, 1995). The development of clay horizons in soils and aquifers reduces the local permeability, affecting the ability of the porous media to transmit water and contaminants, and potentially increasing preferential flow. Clay development in soils can result in seasonal groundwater ponding and vernal pool development and can decrease erosion rates by increasing the cohesive strength of a soil (Hobson and Dahlgren, 1998). Perhaps most importantly, depending on the relative solubilities of the dissolving and precipitating minerals, there is the possibility that clay minerals can strongly control primary mineral dissolution through the removal of weathering products and resulting changes in the reaction affinity of the dissolving minerals.

A number of studies have investigated the dissolution rate of various clays and other important secondary minerals under experimental conditions (Nagy et al., 1991; Nagy and Lasaga, 1992; Nagy, 1995; Huertas et al., 1999; Cama et al., 2000; Cama et al., 2002; Kohler et al., 2003; Kohler et al., 2005). The precipitation rate of clays has also been investigated under experimental situations (Nagy et al., 1991; Nagy and Lasaga, 1992, 1993; Yang and Steefel, 2008). The rates of clay precipitation in natural systems have been considered in a relatively limited number of natural systems, typically using an inverse mass balance approach (Yokoyama 
and Banfield, 2002; Price et al., 2005) or a reactive transport model approach (Godderis et al., 2006). Studies of mineral dissolution in groundwater systems (Zhu, 2005; Zhu et al., 2006) and at the catchment scale (Godderis et al., 2006) have also noted the importance of clay precipitation and the associated thermodynamic parameters. However, there has not been a detailed analysis of the rates of clay formation in a natural weathering system that considers the primary mineral dissolution rates, aqueous transport, distance from chemical equilibrium, and pore water chemistry.

It is difficult to measure precipitation rates under geologically meaningful conditions using experimental approaches. Reactive transport simulations of natural systems using detailed measurements of fluid compositions and mineral abundances offer a potentially useful means of quantifying secondary mineral precipitation rates and of examining the extent to which secondary mineral precipitation controls primary mineral dissolution. However, there are significant difficulties in determining mineral kinetics in natural systems associated with natural heterogeneity, the potential for variations in mineral solubility and reactive surface areas, seasonally variable moisture contents and elemental cycling by vegetation, and the many simplifications and assumptions required to represent a natural system as an approachable mathematical problem.

This study uses a reactive transport approach (the multi-component model CrunchFlow) to directly investigate how secondary mineral precipitation and solute transport control primary mineral weathering rates using data on soils of different ages from a chronosequence developed on elevated marines terraces near Santa Cruz, CA. The reactive transport model uniquely allows us to quantitatively evaluate the effect of reaction networks on the observed geochemical trajectories. Detailed measurements of the mineral abundances, hydrology and aqueous concentrations reported in companion papers (White et al., 2008; this issue) permit characterization of weathering processes on a detailed level comparable to many laboratory studies. Given the robust geochemical data for the Santa Cruz Terraces, it is possible to uniquely identify weathering processes in order to constrain the factors that control chemical weathering rates, including the important roles of secondary minerals, aqueous transport and the approach to thermodynamic equilibrium.

\section{SITE DESCRIPTION}

The study site consists of a sequence of five marine terraces located within and northwest of the city of Santa Cruz, CA, adjacent to the Pacific Ocean (Fig. 1). This paper will use the same terrace identifications as presented in the previous papers on the Santa Cruz chronosequence in which the successively older terraces are termed SCT 1 to SCT 5 (See Table 1 in White et al., 2008 for a more detailed discussion of terrace nomenclature). The average annual rainfall at Santa Cruz, CA is $727 \mathrm{~mm}$ and the average temperature is $13.4^{\circ} \mathrm{C}$. The age of the terraces, regional geology, climate, and the primary soils data are discussed in White et al. (2008); therefore only a brief summary is provided here. The climate is Mediterranean with cool wet winters and hot dry summers. The marine terraces originated as wave cut platforms during high sea level stands and were subsequently stranded above sea level by tectonic uplift of the Santa Cruz Mountains (Anderson et al., 1999). The bedrock platform of each terrace is covered with 1 to 10 meters of sediment, principally sands, derived primarily from long shore marine transport of local fluvial sediments eroded from the Santa Cruz Mountains (Perg et al., 2001). Sampling sites at each of the five terraces were chosen based on several criteria, including the lack of significant erosion, lateral distance from the edges of the relict sea-cliff, and absence of anthropogenic disturbance (White et al., 2008). Each terrace (65 ka, $90 \mathrm{ka}, 137 \mathrm{ka}, 226 \mathrm{ka}$ ) was modeled, but only the details of the oldest terrace, SCT5 $(226 \mathrm{ka})$, are considered here because this older terrace shows the greatest degree of chemical weathering and profile development (Fig. 2). 


\section{MODEL FORMULATION AND MODEL CONSTRAINTS}

The model used in this study is the CrunchFlow multicomponent reactive transport model (Steefel and Lasaga, 1994; Steefel and Yabusaki, 1996; Steefel, 2001; Giambalvo et al., 2002; Maher et al., 2006b). A model formulation was developed that described the progressive evolution of terrace weathering in order to reproduce the observed data for the oldest $226 \mathrm{ka}$ terrace (SCT 5). In addition to individual rate laws describing mineral dissolution and precipitation, the model also includes mineral-specific cation exchange and uses the measured flow rate and water contents to describe unsaturated zone flow and transport. The mineral abundance profiles, major element profiles, exchangeable cations, and aqueous data are used as constraints in the modeling. The abundance of data enables us to uniquely consider the relationships between profile geometry, secondary mineral precipitation, the departure from thermodynamic equilibrium and aqueous transport. The stoichiometry of the overall reactions serves as an additional constraint. Given the large number of available constraints, we are also able to consider the effect of both end-member mineral compositions and solid solution compositions on calculated mineral weathering rates. The parameters for the model are based on literature data, measured values summarized in White et al (2008, this issue), best approximations from the data, or for cation exchange, modeling of the data using the nonlinear optimization program PEST (Steefel et al., 2003; Doherty, 2004).

\subsection{Primary and Secondary Minerals}

Mineral compositions and abundance profiles for all terraces and present day beach deposits, reported in White et al. (2008), were determined by electron microprobe and quantitative X-ray diffraction (XRD) using the methods of Eberl (2003). In situ weathering of the terrace material produces depth- and age-dependent mineralogical and elemental profiles, including the progressive accumulation of kaolinite culminating in the pronounced argillic horizon observed in SCT 5 (Fig. 2). The primary protolith minerals observed in the deepest terrace horizons, are quartz, K-feldspar, plagioclase, and smectite. The Purisima Formation, which outcrops in present day sea cliffs and in the submarine shelf, is the parent material for the fine grained component in the terraces and contains 3 to $5 \mathrm{wt} \%$ smectite. Based on the compositional similarity between the terrace and Purisima smectite, it is assumed that terrace smectite is a primary mineral and is not actively forming in the soil profile (White et al., 2008). This is substantiated by the weathering gradients observed in the smectite abundance profiles and the observed decrease in total cation exchange capacity, which also suggests a loss of exchange sites over time due to smectite dissolution. The secondary minerals in the shallower weathered horizons are kaolinite and minor amounts of iron oxides. The reversals in primary mineral content in the upper 1 meter of the profiles are thought to result from eolian inputs. This may have occurred episodically with enhanced deposition during glacial periods when the sea level was lower, or as a continuous flux over the development of the soil profile. The effects of eolian accumulation on the calculation of weathering rates and profile development will also be considered.

The composition, equilibrium constants and surface areas of the minerals and related parameters are detailed in Table 1. As no direct measurements of plagioclase solubility as a function of anorthite content are available, three model scenarios were considered in order to understand how this could affect the weathering process. Model 1 considers only pure K-feldspar and albite end-member compositions, similar to previous studies of granitic rocks (White et al., 2002). Models $2 \mathrm{a}$ and $2 \mathrm{~b}$ incorporate the plagioclase and $\mathrm{K}$-feldspar compositions reported in Table 1 and in White et al. (2008). Because the solubility of plagioclase containing $30 \%$ anorthite is greatly enhanced relative to the end-member albite solubility, modifications in either the plagioclase or K-feldspar solubility are required to fit the measured mineral profiles, as discussed in later sections. The measured plagioclase composition in the unweathered terrace deposits is between $\mathrm{An}_{25}$ and $\mathrm{An}_{33}$, with slightly lower anorthite contents in the Terrace 5 sediments $\left(\mathrm{An}_{10}\right.$ to 
$\mathrm{An}_{20}$ ) (White et al., 2008, Table 2). It is not known if the compositional variability reflects differences in the original terrace material or the presence of heterogeneous populations of plagioclase with differing anorthite contents.

As the thermodynamic values for feldspar solid solutions are difficult to constrain, two options were evaluated. A full justification for the options considered is provided in the Results section, but the $\log K \mathrm{~s}$ used in the calculations are provided in Table 1 for completeness. Model 2a considers a plagioclase $\left(\mathrm{An}_{30}\right)$ composition using an equilibrium constant determined from the Santa Cruz chronosequence data (mineral abundance and elemental), and a pure end-member Kfeldspar composition with the same solubility as in Model 1 . Model $2 \mathrm{~b}$ alternatively considers the effect of $\mathrm{An}_{30}$ using the equilibrium constant calculated from the data of Arnorsson and Stefansson (1999) and determines instead the solubility of the K-feldspar with 20 mol \% albite as measured for SCT5. In both cases, the rationale is to honor the mineral and elemental profile data, which constrains the relative solubility of the two feldspar phases.

Several different smectite and mixed-layer clay compositions and solubilities were considered by using the measured aqueous data to calculate the aqueous saturation state. A smectite of a similar composition to that reported for terrace material in eqn. 2 of White et al. (2008) was treated as a primary dissolving mineral phase. This composition was selected because it was both closest in composition to the measured smectite and reached thermodynamic equilibrium over the upper 4 meters of the profile, consistent with the observed smectite dissolution over this depth and generally consistent with calculated saturation states for smectite using the measured aqueous compositions from White et al. (this issue).

The predominant secondary mineral at SCT 5 is kaolinite. A review of existing thermodynamic data for kaolinite equilibrium constants at $25^{\circ} \mathrm{C}$ revealed large variations commonly exceeding one order of magnitude (Grimaud et al., 1990; Nagy et al., 1991; Devidal et al., 1996). The variability may result from difficulty in measuring low Al concentrations, differences in the crystallinity, and compositional variations substantial enough to affect the overall solubility. We used the solubility of Georgia kaolinite determined by Yang and Steefel (2008) at $22^{\circ} \mathrm{C}$, which was consistent with Nagy et al. (1991) but $0.8 \log$ units more soluble than the EQ3/EQ6 value (cf. Wolery et al., 1990). XRD data did not show evidence for a more soluble precursor phase such as halloysite (White et al., this issue). However, the kaolinite was observed to be relatively fine-grained and poorly crystalline. The effect of different equilibrium constants on the interpretation of kaolinite rates is discussed in Appendix 1.

\subsection{Mineral Surface Areas}

The bulk reactive surface area $\left(\mathrm{m}^{2} / \mathrm{m}^{3}\right.$ bulk $)$ for mineral precipitation and dissolution in the model is calculated from the specific surface area $\left(A_{\text {spec }}\left(\mathrm{m}^{2} / \mathrm{g}\right)\right)$ :

$$
A_{\text {bulk }}=\frac{\phi_{m} A_{\text {spec }} M W_{m}}{V_{m}}
$$

where $\phi_{m}$ is the volume fraction of the mineral, $M W_{m}$ is the molecular weight of the mineral and $V_{m}\left(\mathrm{~m}^{3} / \mathrm{mol}\right)$ is the molar volume of mineral. This is the preferred approach for modeling precipitation of secondary phases because evolution of the mineral volume fraction causes the bulk surface area to evolve according to Eqn. 1.

Mineral surface areas were determined using several different methods; the assumed values and ranges are listed in Table 1. BET measurements on the bulk sediment from terrace 5 ranged from $5 \mathrm{~m}^{2} / \mathrm{g}$ in the upper and lower portions of the profiles to as much as $50 \mathrm{~m}^{2} / \mathrm{g}$ in the argillic horizons where secondary mineral accumulation is at a maximum and primary mineral contents are quite low. Surface areas of the primary minerals were determined by White et al. (2008) using a geometric specific surface area $\left(A_{\text {geo }}\right)$ based on the average grain size and feldspar abundances $\left(0.012 \mathrm{~m}^{2} / \mathrm{g}\right.$ for plagioclase) and a surface roughness $(\lambda)$ of 160 based on the 
relationship between material age and surface roughness presented in White and Brantley (2003). The resulting specific surface area $\left(A_{\text {spec }}\right)$ of $1.94 \mathrm{~m}^{2} / \mathrm{g}$ most likely provides a maximum estimate of the surface area and therefore our calculated rate constants are likely to represent minimum values. As the protolith material was a well-sorted and uncemented beach sand, mineral surface areas are not likely to vary from our estimate as a result of cementation that occludes mineral surfaces.

\subsection{Aqueous transport}

The spatial distribution of gravimetric moisture contents vary seasonally in the upper terrace soils, with saturated conditions occurring for several months during the wet season (Fig. 12, White et al., this issue). The maximum moisture contents correspond to the zones of peak clay accumulation. During the dry season, extensive profile drying is generally confined to the shallower depths above the argillic horizon. Beneath the argillic horizon the soil remains unsaturated, but the moisture contents remain essentially constant between seasons. Pump tests suggested minimal lateral flow through the argillic horizon. Perennial groundwater encountered at or near the maximum sampling depth (ca. $10 \mathrm{~m}$ ) was observed to fluctuate seasonally by about 2 meters at SCT 5.

The measured bulk density and gravimetric water contents contained in White et al. (this issue) were used to calculate the pore water liquid saturation profile that was incorporated into the model to formulate unsaturated flow and transport. Although this liquid saturation reflects the modern conditions at SCT5, the water content profiles are quite similar between SCT5 and SCT1 (65 ka) suggesting that modern liquid saturation may provide a reasonable estimate of the longterm conditions. In addition, measured soil tensions and water contents showed minimal seasonal variations beneath the depth of the argillic horizon.

The generally flat terrace surfaces generate little to no runoff and are maximally conducive to vertically downward unsaturated flow. Vertical infiltration fluxes $(q)$ at each terrace were calculated using the chloride mass balance (CMB) approach as discussed in White et al. (this issue). The calculated value for SCT 5 is $0.088 \mathrm{~m} / \mathrm{yr}$. The values calculated at the other four terraces range from approximately 0.086 (SCT1) to $0.218 \mathrm{~m} / \mathrm{yr}$ (SCT 4). The initial conditions and boundary conditions used in the model calculations are summarized in Table 2 and discussed in the following sections.

\subsection{Aqueous chemistry}

The hydrochemistry is described in detail in White et al. (this issue). Data include precipitation (rainfall) amounts and compositions, soil matric potentials, and detailed chemistry for pore water collected from nested porous cup suction water samplers. The precipitation amounts ranged from $390 \mathrm{~mm} / \mathrm{yr}$ at SCT1 to $586 \mathrm{~mm} / \mathrm{yr}$ at SCT 5, presumably due to orographic effects of increasing elevation of the terraces with increasing distance from the coast (White et al., 2008). Coastal fog during the dry season also constitutes a portion of the moisture inputs at the site. Solute concentrations, dominated by $\mathrm{NaCl}$ deposition, generally decreased with distance from the coast. Measurements of precipitation at each terrace suggest that sea spray is an important source of solutes in precipitation. Soil gas samples for $\mathrm{CO}_{2}$ and $\mathrm{O}_{2}$ were collected from stainless steel gas samplers following the procedure of White et al. (2005b). Because the pore water samples degas during collection, the measured $\mathrm{CO}_{2}$ and alkalinity values were used to calculate the field $\mathrm{pH}$. The $\mathrm{pH}$ values calculated based on the measured carbonate alkalinity and the soil gas $P \mathrm{CO}_{2}(0.01$ bars $)$ range from 7.0 to 5.5, generally increasing with depth.

For the model simulations, the measured precipitation was corrected for evaporation (ET) on the basis of the measured soil water chloride concentrations (average ET $=75 \%$ at SCT 5). The measured solute concentrations within the profile were used to calculate the saturation state 
of the minerals for comparison with model results (Table 2). Total dissolved aluminum concentrations were high in the shallow soils and positively correlated with dissolved organic carbon (DOC), indicating probable complexation with organic matter above 1meter depth (White et al., this issue). However below the argillic horizon $(>1 \mathrm{~m})$ total $\mathrm{Al}$ as well as DOC decreased significantly. The deeper $\mathrm{Al}$ values therefore more accurately reflect free-Al and states of mineral saturation.

\subsection{Cation Exchange}

The aqueous and ammonium acetate exchangeable $\mathrm{Na}^{+}, \mathrm{K}^{+}, \mathrm{Ca}^{2+}, \mathrm{Mg}^{2+}$, and $\mathrm{Sr}^{2+}$ were measured at each terrace and reported in Appendix III in White et al. (this issue). The bulk cation exchange capacity (CEC) (assumed to reflect complete base cation saturation at soil water $\mathrm{pH}$ ) in individual terraces was observed to correlate strongly with smectite concentrations and less strongly with kaolinite concentrations (White et al., 2008). This relationship is expected since the typical cation exchange capacity (CEC) of kaolinite and smectite generally ranges from 2-10 meq/100g and 80-100 meq/100g respectively (Ma and Eggleton, 1999; Borden and Giese, 2001; Coppin et al., 2002). The different capacities of the two cation exchangers should thus result in a net decrease in total CEC over time as smectite is progressively weathered to kaolinite.

In order to reflect the changing composition of the total cation exchange pool, a model for mineral-specific cation exchange was developed for use in CrunchFlow. This formulation linked the abundance of cation exchange to the abundance of the particular mineral using the mineralspecific CEC. We considered the ammonium acetate exchangeable and aqueous data for $\mathrm{K}^{+}, \mathrm{Na}^{+}$, $\mathrm{Ca}^{2+}, \mathrm{Mg}^{2+}$, and $\mathrm{Sr}^{2+}$, along with the mineral abundances for kaolinite and smectite from all terraces as determined by XRD and reported in White et al. (2008; this issue). The GainesThomas activity convention was used to formulate multicomponent exchange in CrunchFlow (Steefel et al., 2003) using a formulation similar to that of PHREEQC (Parkhurst and Appelo, 1999). The reaction stoichiometry of the following form was used to calculate selectivities for the major cations $\left(\mathrm{K}^{+}, \mathrm{Na}^{+}, \mathrm{Ca}^{2+}\right.$ and $\left.\mathrm{Sr}^{2+}\right)$ relative to $\mathrm{Mg}^{2+}$, for exchange on both kaolinite and smectite:

$$
\frac{1}{2} M g^{2+}+\frac{1}{m} M X_{m} \leftrightarrow \frac{1}{2} M g X_{2}+\frac{1}{m} M^{m+}
$$

where $M$ is the competing cation, $m$ is the charge of the cation and $X$ is the exchange site. Aqueous and exchangeable cations and measured mineral volume fractions from the entire thickness of the four terrace profiles were used to constrain the cation exchange selectivites (relative to $\mathrm{Mg}^{2+}$ ) and the smectite and kaolinite CECs in CrunchFlow using the nonlinear optimization program PEST. The data from SCT 4 were excluded because of evidence for largescale anthropogenic disturbance during operation of a lime kiln (White et al., 2008). The mineral-specific CECs and selectivities were determined by minimizing the sum of the squared weighted residuals. Low concentration values (e.g. $\mathrm{K}^{+}$) were weighted such that all concentrations were given equal importance. The optimized values are shown in Table 3 and the fit to the data shown in Fig. 3. These values were then used in the model simulations to consider the effect of changes in cation exchange driven by mineral dissolution and precipitation as described above.

Individual terraces were also considered separately, producing similar values to the global values presented in Table 3. However, in the upper depths of several terraces (notably SCT 3 and 5 , ca. 0 to $1 \mathrm{~m}$ ), we found evidence for a different type of exchange medium with very different selectivities. This exchanger is most likely soil organic matter. As a result of this finding, the shallow samples from SCT 3 and 5 were excluded from the global fit. The global CEC values determined are $86 \mathrm{meq} / 100 \mathrm{~g}$ and $9.4 \mathrm{meq} / 100 \mathrm{~g}$ for smectite and kaolinite respectively. These values are in a similar range to those calculated using EXCEL reported in White et al (this issue): 108 to $63.7 \mathrm{meq} / 100 \mathrm{~g}$ for smectite and 36 to $1.6 \mathrm{meq} / 100 \mathrm{~g}$ for kaolinite. 


\subsection{Alternative rate law formulations}

There have been several proposed kinetic rate law variations describing aluminosilicate dissolution stemming from both theoretical and experimental observations (Aagaard and Helgeson, 1982; Lasaga, 1984; Gautier et al., 1994; and many others; Hellmann, 1994; Oelkers et al., 1994; Hellmann and Tisserand, 2006). In order to evaluate the application of these rate laws to natural system studies we considered three alternatives: 1) a linear Transition State Theory (TST) rate law (L-TST) of the form proposed by Aagaard and Helgeson (1982) and Lasaga (1984) as a reference model, 2) a TST rate law that defines the rate-limiting step as the formation of a silica-rich precursor complex on the surface of the feldspar, thus accounting for the inhibitory effects of aqueous Al (AIM)(Gautier et al., 1994; Oelkers et al., 1994; Carroll and Knauss, 2005), and 3) a parallel rate law formulation that describes close-to-equilibrium dissolution separately from far from equilibrium dissolution (PRL)(Hellmann and Tisserand, 2006).

A general form of the TST rate law formulation that is not restricted to the assumption of a linear dependence on the deviation from equilibrium can be written as:

$$
R_{l}=A_{b u l k} \cdot k_{l} \cdot \beta \cdot\left[1-\exp \left(\frac{-\Delta G_{r}}{\sigma R T}\right)^{n}\right]^{m}
$$

where $R_{l}$ is the rate of an individual reaction pathway or mechanism (in units of $\mathrm{mol} / \mathrm{m}^{3}$ porous medium $/ \mathrm{s}), A$ is the reactive surface area $\left(\mathrm{m}^{2} / \mathrm{m}^{3}\right.$ porous medium), $k_{l}$ is the surface normalized rate constant $\left(\mathrm{mol} / \mathrm{m}^{2} / \mathrm{s}\right), \beta$ is a term describing the inhibition or catalysis of the reaction, $\Delta G_{r}$ is the Gibbs free energy of reaction, $n$ and $m$ are fitting parameters, and $\sigma$ is Temkin's average stoichiometric coefficient. The overall rate of mineral $k$ is given by the sum of the parallel reaction pathways (as in the PRL form)

$$
R_{k}=\sum_{l} R_{l}
$$

The reference model is formulated using a linear Transition State Theory rate law (L-TST) for reversible reactions with a linear dependence on the deviation from equilibrium. The L-TST model is formulated assuming $\beta, \sigma, m, n$ are equal to 1 . This L-TST expression was previously used in the spreadsheet calculator described by White et al. (2008) to fit Santa Cruz feldspar weathering profiles.

The alternative model formulations in CrunchFlow were discussed previously in Maher et al. (2006b), therefore only a brief summary is presented here. The Al-inhibition model (AIM) is based on the principle that aluminosilicate dissolution rates are controlled by the formation and destruction of an Al-deficient and Si-rich precursor complex (Gautier et al., 1994; Oelkers et al., 1994; Carroll and Knauss, 2005). This is considered here by modifying the inhibition term in equation 1 to include a hyperbolic dependence on $\mathrm{Al}$ activity:

$$
\beta=\frac{K_{f}^{\prime}}{\left(\left[\mathrm{Al}(\mathrm{OH})_{3}\right]^{1 / 3}+K_{f}^{\prime}\right)}
$$

where $K_{f}^{\prime}\left(10^{-4.824}\right)$ is the equilibrium constant for the reaction describing the precursor complex and is calculated from the experimental data of Carroll and Knauss (2005) as described in Maher et al. (2006b). For this formulation $\sigma$ is also equal to $1 / 3$ to reflect the stoichiometry of the overall dissolution reaction relative to the stoichiometry of the rate-limiting step, here the formation of the silica-rich precursor. With this formulation, the exponents $n$ and $m$ in Equation $3 \mathrm{a}$ are assumed to $\mathrm{be}=1$.

The third formulation, PRL, combines two parallel nonlinear rate laws that are summed according to Equation 1.1 and is based on theoretical principles and experimental data that suggest close-to-equilibrium dissolution behavior is fundamentally distinct from far-fromequilibrium dissolution (Burch et al., 1993; Hellmann and Tisserand, 2006). The rate law 
proposed by Hellmann and Tisserand (2006), based on experimental data for albite, was implemented in CrunchFlow to consider both the plagioclase and K-feldspar dissolution in the profiles and is very similar in form to the parallel rate law previously proposed by Burch et al. (1993). One rate law describes far from equilibrium dissolution behavior with a rate constant $\mathrm{k}_{2}$, and one rate law describes close to equilibrium behavior $\left(\mathrm{k}_{1}\right)$ :

$$
R_{l}=A_{b u l k} \cdot k_{1}\left[1-\exp \left(-m_{1} g^{m_{2}}\right)\right]+k_{2}[1-\exp (-g)]^{m_{3}}
$$

where $g$ represents $\left|\Delta G_{r}\right| / R T$ and the fitted parameters $m_{1}, m_{2}$ and $m_{3}$ have values of $7.98 \times 10^{-5}$, 3.81 and 1.17 (Hellmann and Tisserand, 2006). This formulation is consistent with theoretical and experimental considerations which suggest that far-from-equilibrium dissolution is characterized by the opening of etch pits and rapid propagation of step waves, whereas close-to-equilibrium dissolution in the absence of etch pits is localized to surface defects (Lasaga and Luttge, 2001; Beig and Luttge, 2006).

The rate constants determined by Hellmann \& Tisserand (2006) were corrected for $\mathrm{pH}$ and temperature. To correct from $\mathrm{pH} 9.2$ to neutral $\mathrm{pH}$, we assumed the relationship between $\mathrm{pH}$ and the rate constant in the alkaline range is defined by a slope of -0.3 (White, 1995) and the rate constants were corrected to the $\mathrm{pH}$-independent range (approximately 1 order of magnitude decrease in the rate constant). The temperature was corrected from $150{ }^{\circ} \mathrm{C}$ to $13.5{ }^{\circ} \mathrm{C}$ assuming the activation energy of $60 \mathrm{~kJ} / \mathrm{mol}$ determined by Hellmann and Tisserand (2006). The corrected rate constants along with the values of $m_{1}, m_{2}$ and $m_{3}$ are reported in Table 4 . The temperature dependence of these fitting parameters have not yet been determined, so the assumption is made that they apply at $25^{\circ} \mathrm{C}$. Given the circumneutral $\mathrm{pH}$ values at SCT5, we assume that mineral dissolution kinetics are independent of $\mathrm{pH}$ (White, 1995).

For each rate law, the rate constants were increased from a starting value equal to that of the laboratory-derived rate constants from Table 4, and were adjusted to fit the gradient in the observed mineral abundance profiles. We used the linear TST model to describe the precipitation of kaolinite. We did not test alternative rate laws for kaolinite precipitation at this time, although we recognize that alternative formulations have been proposed (Yang and Steefel, 2008).

\subsection{Model conditions and parameters}

The model simulations were run at $13.5{ }^{\circ} \mathrm{C}$ (mean annual air temperature) and $1 \mathrm{~atm}$. The model domain for each terrace profile consists of a one dimensional soil column with a flux boundary condition at the base of the measured profile, and a Dirichlet boundary condition for aqueous and gaseous species at the land-atmosphere interface. For SCT 5, the model was run for $226 \mathrm{ka}$, but equally spaced time intervals corresponding to the approximate age of the other terraces are shown for comparison. The protolith composition determined from the deepest sediments represents the initial solid condition (Table 1, Fig. 5). The composition of the infiltrating fluids is the composition of the volume-weighted precipitation corrected for evapotranspiration based on the chloride mass balance estimate (Table 2). The flux of water entering the column is taken as equal to the long-term average infiltration flux of $0.088 \mathrm{~m} / \mathrm{yr}$ determined by chloride mass balance fir SCT 5 (White et al., this issue).

The best-fit to the data was determined by matching the solid profiles using flow rate determined by the chloride mass balance and varying the kinetic rate constants. The reverse parameter estimation program (PEST, Doherty, 2004) was used to evaluate the sensitivity and uniqueness of the model fit and is described in more detail in Appendix 2. PEST was used to evaluate the kinetic rate constants and the flow rate based on the measured solid and solute profiles. 


\section{RESULTS}

\subsection{Base case model}

\subsubsection{Profile evolution for end-member compositions}

Model mineral abundance profiles reflecting different time steps in the soil evolution are shown in Fig. 4, along with profiles showing the overall rates versus terrace depth. These profiles represent the best fit to the data using the end-member stoichiometry (Model 1) and the linear TST model. Other stoichiometry, solubilities and rate law formulations will be discussed in the following sections and an analysis of the sensitivity and uncertainty is provided in Appendix 2. The calculated albite and K-feldspar rate constants are nearly identical, although the solid profiles show very different slopes and degrees of weathering. As the K-feldspar profile propagates downward, the slope of the profile remains constant, which is consistent with the observation that pore waters approach equilibrium for this phase rapidly relative to albite (Fig. 5). Similar conclusions concerning the similarity in albite and K-feldspar rate constants and the importance of respective saturations were reached previously using a much simpler spreadsheet approach to fit the SCT 5 profile (Fig. 14, White et al., 2008).

The albite profile suggests a markedly different evolution from K-feldspar because it has a greater solubility. This difference is less evident in the saturation state profiles (Fig. 6), but is clearly evident in the mineral abundance and rate profiles of Fig. 5. Over the depth range considered, the pore waters remain very slightly undersaturated, thus resulting in a weathering profile that broadens over time. This effect is evident in the rate profiles - the peak reaction rate decreases and the weathering front continues to broaden. This result differs from those obtained with the simple linear estimate of steady-state profile development reported in White et al. (2008). The reasons for the discrepancy will be discussed in the following sections.

The evolution of the kaolinite profile is approximately the inverse of the albite profile, with kaolinite accumulation occurring at increasingly greater depths over time as a result of depletion in primary minerals at the top and the downward transport of aqueous weathering products. This indicates that $\mathrm{Al}$ is largely conserved in this $\mathrm{pH}$ range, as expected. The model profile shows a small reversal in the upper 0 to 0.5 meters because of undersaturation of kaolinite, (Fig. 4f). The twin peaks in the kaolinite rate profiles correspond to the peak reaction rates of the primary dissolving minerals (albite and K-feldspar). The maximum accumulation of kaolinite corresponds to the point in time where the primary mineral reaction fronts overlapped. The continued accumulation of kaolinite at greater depths, as suggested by both the data and the model, is consistent with our suggestion that albite closely approaches but does not reach equilibrium over the depth of the profile.

\subsubsection{Primary mineral stoichiometry and solubility}

If a solubility for $\mathrm{An}_{30}$ plagioclase content is used (rather than the end-member value for albite), then the reactive transport simulations are unable to reproduce either the measured profile gradient of plagioclase or the position of the plagioclase profile relative to that of K-feldspar. The increase in solubility of plagioclase relative to K-feldspar (and albite) steepens the plagioclase profile gradient and increases the amount of kaolinite precipitation. Changes in mineral kinetics and other parameters such as flow rates cannot be used to improve the model fit because the relative position of the weathering fronts under quasi-steady state weathering conditions is fixed only by the relative solubilities (cf. Ortoleva et al., 1987; Lichtner, 1993; White et al., 2008). This conclusion is also borne out by numerical simulations using CrunchFlow (not shown here) in which it was confirmed that the relative position of the Kfeldspar and plagioclase front could not be achieved by changing flow rates and/or mineral reaction kinetics. 
Given that the position of the weathering fronts are fixed by the relative mineral solubilities, there are two options for increasing the agreement between the solid solution models and the measured profiles using the measured plagioclase and K-feldspar compositions. The first option (Model 2a) is to use the mineral and elemental profiles to independently determine the log $\mathrm{K}$ for $\mathrm{Ab}_{70} \mathrm{An}_{30}$, while using the pure K-feldspar composition and other parameters of Model 1 . Fitting the profile data, this approach results in a $\log \mathrm{K}\left(25^{\circ} \mathrm{C}\right)$ of 8.17 for a plagioclase with $30 \%$ anorthite. For Model 2a, all calculated rate constants remain the same.

If instead a $\log \mathrm{K}\left(25^{\circ} \mathrm{C}\right)$ value of 9.63 is assumed for $\mathrm{Ab}_{70} \mathrm{An}_{30}$ based on the calculations of Arnorsson and Stefansson (1999), then the K-feldspar $\left(\mathrm{Ab}_{20}\right) \log \mathrm{K}\left(25^{\circ} \mathrm{C}\right)$ must be increased by $1.2 \log$ units to 2.63 to fit the profile data (Model $2 \mathrm{~b}$ ). Reported $\log \mathrm{K}$ values for K-feldspar with $20 \mathrm{~mol} \%$ albite content range several orders of magnitude from approximately 1.07 for sanidine to 5.5 for microcline at $25^{\circ} \mathrm{C}$ (Arnorsson and Stefansson, 1999), bracketing the values determined by fitting the profile data. When both the plagioclase and K-feldspar solubilities are increased in Model $2 \mathrm{~b}$, the data require a decrease in the kaolinite rate constant by four orders of magnitude. This model presents the best fit to the solid profile elemental data at depths greater than about 2.5 meters (Fig. 6), but does not match the aqueous data and re-calculated thermodynamic saturations with the exception of the deepest sample at 6 meters. In contrast, Model 2 a remains consistent with the pore water compositions and the calculated saturation state values and provides a reasonable fit to the elemental profiles at depths less than about 2.5 meters (Fig. 6). The enrichment of relative and total Ca contents observed at the top of the profile is most likely a result of eolian inputs and cannot be captured with either Model 2a or 2b. Most importantly, these changes in stoichiometry and solubility do not change the primary mineral rate constants using Models $2 \mathrm{a}$ and $2 \mathrm{~b}$ because the relative depth of the profiles is controlled only by the relative mineral solubilities.

In addition to the thermodynamic constraints imposed by the relative positions of the reaction fronts, textural considerations may also be important for interpreting these results. The increasing $\mathrm{Al} / \mathrm{Si}$ crystallographic ordering, resulting from slow cooling of plagioclase between temperatures of 800 and $400^{\circ} \mathrm{C}$ (conditions common for granitic plutons) produces complex and extremely fine scale lamellae structures which consist of zones of sodic and calcic enrichment (Carpenter, 1993). The fine-scale intergrowth of these plagioclases could potentially result in armoring of the anorthite component during dissolution and would thus be consistent with a model in which end-member albite solubility eventually controls the pore water chemistry at larger extents of weathering. This model would explain the better fit of the pore water data using a $\log \mathrm{K}$ more like that of an albitic plagioclase, as is the case with Model 1 and Model 2a. This explanation would also be consistent with the observed reduction in anorthite content with terrace age (White et al., 2008). Because none of the alternative models we considered produces a suitable match to all of the fluid and solid data across all metrics, coupled with the constraints that the profile geometries impose on relative solubility (constraints violated by Models $2 \mathrm{a}$ and $2 \mathrm{~b}$ ), we conclude that in the present case the processes and rates that we consider here are well described by Model 1, therefore only Model 1 will be referred to in the following discussion.

\subsubsection{Solute profiles and mineral saturation states}

The solute profiles offer an additional constraint on the model results and also indicate profiles that are impacted by processes (biologic or hydrologic) that are not explicitly considered in the model formulation (Fig. 7). Fig. 7 shows the best fit to the data determined using the LTST model and the measured infiltration flux $(0.088 \mathrm{~m} / \mathrm{yr})$. The model fits to the $\mathrm{pH}$, and total $\mathrm{Na}^{+} \mathrm{Mg}^{2+}, \mathrm{Al}^{3+}$ and $\mathrm{SiO}_{2}(\mathrm{aq})$ profiles are in general agreement with the measured data. In particular, the model Al concentration profile reproduces the measured data and suggests an accumulation of $\mathrm{Al}$ in the upper pore waters. The $\mathrm{K}^{+}$profile, however, is notably discrepant despite the excellent match to the K-feldspar profile. The exact reason for this has not been determined, but probably results from strong seasonal biologic cycling of $\mathrm{K}^{+}$, which is the 
dominant mineral nutrient in the grassland vegetation (White et al., this issue). The model $\mathrm{pH}$ also differs slightly from the measured values (which were calculated from measured soil $\mathrm{PCO}_{2}$ and alkalinity). The differences may reflect slight measurement error or slight seasonal fluctuations. However, any error introduced by the difference in $\mathrm{pH}$ will only affect our interpretation of secondary mineral precipitation as discussed in Appendix 1.2.

As we are primarily concerned with the primary mineral dissolution and secondary mineral precipitation, the match to $\mathrm{Al}^{3+}$ and $\mathrm{SiO}_{2}$ (aq) concentrations and saturation states (Figs. 5 and 7) provides an additional constraint on the reaction rates over and above what is provided by a match of the time-integrated mineral profiles. The model is in very close agreement with the measured saturations states for all three minerals beneath 1.5 meters and confirms the high degree of supersaturation of kaolinite suggested by the data. The model also suggests that as mineral volumes are depleted and reaction rates decrease, undersaturation with respect to ?? increases over time at a particular point within the profile, which is consistent with the trend in calculated saturation states for the other younger terrace profiles (White et al., this issue). The reversal in measured values is at the top of the profiles is most likely an effect of eolian inputs as discussed in Appendix 1.

\subsubsection{Cation exchange and the evolution of clay abundances}

The evolution of smectite relative to kaolinite and the bulk CEC is shown in Fig. 8. A dissolution rate constant for smectite of $10^{-15.9} \mathrm{~mol} / \mathrm{m}^{2} / \mathrm{sec}$ was determined by approximating the observed profile gradient. At $226 \mathrm{ka}$, smectite dissolution in the model occurred only in the upper $4 \mathrm{~m}$, at which point it reached equilibrium. Smectite dissolution had an extremely minor impact on the profiles of the major minerals in the model (e.g. albite, K-feldspar and kaolinite) because of its low abundance. However, as smectite provides a large fraction of the CEC, it needs to be considered. The assumed protolith abundance for smectite abundance is lower than values observed at other terraces, but given the strong agreement with the data it is likely that smectite abundances were lower in these terrace deposits.

For this particular terrace, the loss of exchange sites from the depletion of smectite in the upper regions of the profile was essentially matched by the large addition of kaolinite with a much lower CEC (Fig 8b,c) resulting in minimal change to the total CEC during profile evolution. Although the total CEC is changing slightly over time due to changes in the volume fraction of kaolinite and smectite, weathering processes operate over much longer timescales than exchange processes, resulting in quasi-steady state conditions. Cation exchange concentrations will be approximately in equilibrium with the advecting waters, therefore, unless a major transient is introduced into the system. As a result, cation exchange is not expected to affect weathering processes. Therefore as expected, the addition of cation exchange coupled to mineral dissolution/ precipitation resulted in no measurable change to the model profile evolution because the weathering and subsequent transport of cations through the profile is slow enough that a quasi-steady state is maintained.

\subsection{Results using alternative rate law formulations}

The system considered here is developed on unconsolidated and well-sorted beach sand where physical surface area restriction and physical heterogeneity are both minimal, therefore these factors are unlikely to substantially impact weathering processes. We also used a maximum surface area estimate (a factor of 160 greater than geometric estimates); therefore these rate constants likely represent minimum values. Using a parallel rate law formulation (PRL), we calculated field scale rate constants consistent with those determined experimentally by Hellmann and Tisserand (2006). Similarly using a rate law formulation that depends on the activity of $\mathrm{Al}$ and a Temkin coefficient of 3 (Equation 3a), we obtain dissolution rate constants within error of 
the laboratory values suggested in Palandri and Kharaka (2004). The model calculations that include a non-linear dependence on reaction affinity (PRL or AIM) are therefore consistent with experimental rate constants for the primary minerals (Table 4). Our values for the rate constants using a linear TST model are similar to typical field-based surface normalized rates (White and Brantley, 2003) and therefore significantly smaller than experimentally-determined rate constants, even though we have accounted for the reaction affinity term in equation $3 \mathrm{a}$ and the observed super saturation of clay minerals.

In Table 4, the best-fit TST rate constants for dissolution of albite and K-feldspar are listed and compared with the results from alternative rate law formulations and with the results from calculations based on the solid profile evolution (White et al., 2008). The rate constants for the parallel nonlinear rate law formulation (PRL) determined from a best fit of the field data were approximately half an order of magnitude slower than the laboratory rate constants calculated by correcting the Hellmann and Tisserand (2006) data for $\mathrm{pH}$ and temperature. The close to equilibrium rate constant $\left(k_{2}\right)$ for the PRL is also similar to the rate constant from the linear TST, indicating that the performance of the parallel rate laws originates from the second, highly nonlinear reaction term in the rate law.

The dissolution rate constants for albite and K-feldspar calculated for the Al-inhibition rate law $\left(10^{-12.7} \mathrm{~mol} / \mathrm{m}^{2} / \mathrm{sec}\right)$ are extremely close to the laboratory reported values of $10^{-12.8} \mathrm{~mol} / \mathrm{m}^{2} / \mathrm{sec}$ (Palandri and Kharaka, 2004). This result is attributable predominanty to the effect of the Alinhibition term in Eqn. 1, as the overall reaction rate must be the same as for the TST and PRL in order to fit the data. As the depth of propagation of the weathering front is in part controlled by the rate of kaolinite precipitation (as discussed in a later section), the kaolinite rate was adjusted slightly between models to achieve a match to the dissolving mineral profiles.

The model calculations that include a non-linear dependence on reaction affinity (PRL or AIM) are therefore consistent with experimental rate constants for the primary minerals (Table 4). Our values for the rate constants using a linear TST model are similar to typical field-based surface normalized rates (White and Brantley, 2003) and therefore significantly smaller than experimentally-determined rate constants, even though we have accounted for the reaction affinity term in equation $3 \mathrm{a}$ and the observed super saturation of clay minerals.

The model albite rate profiles for the three different rate law formulations as a function of saturation state are shown in Fig. 9. The measured saturation state corresponding to the peak overall reaction rate from Fig. $4 \mathrm{e}$ (i.e. the point where the ratio of the profile concentration $\left(M_{w}\right)$ to the protolith value $\left(M_{p}\right)$ equals 0.5$)$ is shown as a reference point in Fig. 9 because this corresponds to the maximum overall weathering rate in the profile.

\subsection{Comparison to previous weathering rate estimates at the Santa Cruz, CA chronosequences}

The linear TST values are also consistent with the aqueous rates determined in White et al (this issue), and those calculated using a spreadsheet model that calculates the dissolution rate as a function of the depletion in the solids (White et al., 2008). The model of White et al. (2008) considered the saturation state of the dissolving minerals as it was affected by mineral dissolution and aqueous transport, and stoichiometrically removed Al and Si to reflect secondary mineral precipitation at the rate at which they were produced from dissolution. The current model treats the reaction kinetics of kaolinite separately using the measured solute and the aqueous activities, and the mineral abundance data. In other words, stoichiometric Al and Si incorporation occurs here with kaolinite supersaturated.

Our comparison of three different rate law formulations suggests that the apparent discrepancy between field and experimental rate constants cannot be attributed entirely to the fact that most field rates are calculated without considering the reaction affinity term. More important 
is the nonlinear dependence of the rate on the reaction affinity as regulated by the slow rates of secondary mineral precipitation. These effects will be discussed in the following sections.

\section{DISCUSSION}

In practice, it is difficult to measure reaction rates experimentally over geologically significant periods of time. Reactive transport simulations of natural systems, constrained by detailed measurements of fluid compositions, hydraulic parameters and mineral abundances, are an alternative method for quantifying reaction kinetics of primary mineral dissolution and secondary mineral precipitation (Giambalvo et al., 2002; Godderis et al., 2006; Maher et al., 2006b). Reactive transport formulations also enable us to test experimental results at the field scale. For the Santa Cruz profiles, we have explicitly considered unsaturated flow, time dependent evolution of mineral-specific cation exchange pools, mineral solubility, secondary mineral precipitation and the effect of alternative rate law formulations (e.g. Al-inhibition and a parallel rate law formulation). In addition, gas phase diffusion is included using a diffusion coefficient of $0.01 \mathrm{~cm}^{2} / \mathrm{sec}$ (Cerling, 1984).

Many authors have discussed the importance of hydrology as a limiting factor for chemical weathering rates in natural systems (White et al., 1992; White and Blum, 1995; Clow and Drever, 1996; Steefel and Lichtner, 1998; Stonestrom et al., 1998; White et al., 1998; West et al., 2005; White et al., 2005a; White et al., 2008; this issue). Previous analysis also documented the importance of fluid fluxes on controlling saturation-limited weathering of primary albite and K-feldspar in the Santa Cruz terraces (White et al., 2008; this issue). Other studies have cited the potential influence of secondary minerals on primary mineral weathering rates (Godderis et al., 2006; Maher et al., 2006b). However, none of these preceding studies considered in detail the kinetic effects of secondary mineral precipitation on weathering of primary minerals. Our investigations show that in the absence of a secondary mineral phase that also removes weathering products from solution, it would require flow rates an order of magnitude greater than our range of estimates to match the amount of observed mineral depletion. In addition, the coupling between the respective dissolution and precipitation kinetics of albite and kaolinite leads to the long-term development of disequilibrium conditions that extend the weathering profiles much deeper into the protolith than predicted by calculations assuming simple equilibrium conditions (White et al., 2008; this issue). We conclude, therefore, that secondary mineral precipitation is important in most weathering systems. If the saturation state of the dissolving minerals is the critical factor controlling chemical weathering rates, then the hydrology, secondary mineral precipitation, relative mineral solubility and other factors which impact $\Delta G_{r}$ will all play a role in controlling the evolution of the weathering profiles. From a practical point of view, interactions between these parameters can only be fully investigated using a modeling approach broadly equivalent to that described in the sections above.

\subsection{Solid state profile development and reaction front geometry}

\subsubsection{Primary mineral dissolution}

Our analysis has demonstrated that the K-feldspar and albite profiles show markedly different gradients with depth because of their different solubilities, not their rate constants, consistent with the conclusions of White et al. (2008). Albite starts to approach equilibrium at the maximum depth of SCT 5 profile $(I A P / K=-0.04$ at 7 meters), whereas K-feldspar reaches equilibrium at relatively shallow depths (3 meters, Figs. 4 and 5). The difference in solubility also results in different patterns for the reaction fronts and peak overall reaction rates, despite the nearly identical rate constants determined for the two minerals. The more soluble albite has a very broad reaction front which extends over the length of the SCT 5 profile, while K-spar reaches 
equilibrium in the upper regions of the profile, and is thus characterized by a short and compressed reaction front and a shallow mineral abundance gradient.

The reaction fronts of the dissolving minerals are also fairly symmetric. The shape of the deeper side is controlled by the approach to equilibrium (or the gradient in $\Delta G_{r}$ values), while the decrease in gradient on the shallow side of the reaction front profile results from the decline in total mineral surface area as the mineral volume decreases. These conclusions are comparable to those also predicted by White et al. (2008) and Brantley et al. (2008). The net result is that the depth of the peak reaction rates corresponds to the location of the profile where the mineral volumes are approximately one half that in the protolith. However, as the leading boundary of the reaction front is controlled by $\Delta G_{r}$, any factors that affect $\Delta G_{r}$ will thus control the rate at which the weathering front propagates, i.e., the weathering advance rate $(\omega)$.

The predicted profile evolution for K-feldspar is consistent with the steady state geometric profile evolution proposed by White et al. (2008) and investigated previously by Lichtner (1993) Steady state profile evolution is defined geometrically as the condition where the mineral abundances at the top of the profile $(z=0)$ are equal to zero $\left(M_{w}=0\right)$, and the mineral abundances at the base of the weathering profile $(z=L)$ are equal to the protolith abundance $\left(M_{w}\right.$ $=M_{p}$ ). In the absence of erosion (as at the Santa Cruz terraces), this condition results in a fixed profile geometry that propagates downward at a constant rate (approximately $9.7 \mathrm{~mm} / \mathrm{kyr}$ ). A requirement for the steady-state profile evolution model is that the mineral must reach thermodynamic saturation in order to maintain a constant weathering gradient. This steady state profile evolution is distinct from steady state soil thickness, which occurs when the weathering advance rate is balanced by the erosion rate (Heimsath et al., 1997), since it occurs even in the absence of erosion.

Because K-feldspar approaches equilibrium, the peak reaction rate does not change substantially over time as the reaction front migrates downward. However, the model albite profile shows a different evolutionary pattern with progressive mass loss at depth that indicates a departure from the steady state geometric profile evolution described by White et al (2008). Although we have chosen the least soluble albite composition, thermodynamic saturation is still not obtained because of kaolinite precipitation. As a result, weathering occurs over the length of the profile (Figs. $4 \mathrm{~b}$ and $4 \mathrm{e}$ ) and the condition that $M_{w}=M_{p}$ is not met. Prolonged weathering has a substantial effect on the reaction rate profile - the peak reaction rate for albite decreases over time as the rate profile broadens. As the reaction front profiles are controlled by mass (and surface area) depletion and thermodynamic saturation, progressive mass depletion and increasing undersaturation broadens the reaction front and reduces the maximum overall dissolution rate. The rate at which the albite profile advances is $23.6 \mathrm{~mm} / \mathrm{kyr}$, about 2.4 times faster than the Kfeldspar front. This value describes the downward propagation of the peak reaction front, but is distinct from the weathering advance rate as at no time after the start of the simulation does $M_{w}$ equal the initial assumed protolith value, $M_{p}$. The implications for this behavior are that in the presence of erosion, steady state profiles can be achieved, but the deep weathering of albite (and especially the Ca-plagioclase compositions) means that $M_{w}$ may not equal $M_{p}$, thus requiring careful consideration of gradients in comparing soil production/weathering advance rates to erosion rates.

An increase in the model dissolution rate constants causes the reaction fronts to become increasingly sharp and the gradients to become shallower, but does not appreciably impact the total mass removed from the profiles (cf. Bolton et al., 2006; White et al., 2008). Our model confirms that the weathering advance rate and the total mass of mineral dissolved will be controlled by the thermodynamic saturation, as is evident by the difference in propagation rates of the reaction fronts for the two minerals. The flow rate and the rate of secondary mineral precipitation are the two predominant controls on the thermodynamic saturation of the dissolving minerals, and as such exert a substantial control over the maximum reaction rates, mass depletion and weathering advance rate. While the importance of the fluid flux in controlling the rate of 
advance of the weathering front under transport-limited conditions has been investigated in previous papers (White et al., 2008), the kinetics of secondary mineral precipitation and the effect of $\Delta G_{r}$ has not.

\subsubsection{Secondary mineral precipitation and the development of an argillic horizon}

Both the measured and model profiles suggest a peak in clay abundances between 0.5 and 2 meters (Fig. 4). This bulge in clay accumulation (referred to herein as the argillic horizon) is common to soils in temperate climates (USDA, 1999). The genesis of an argillic horizon is not well understood, but is commonly attributed to translocation of clays from the A horizon (the "zone of elluviation") and accumulation in the B horizon (the "zone of illuviation"). Inspection of the bulk reaction rates shown in Fig. 4 suggests that the bulge in the argillic horizon results from the overlap of the albite and K-feldspar reaction fronts early in the profile development at approximately $65 \mathrm{ka}$ of soil formation. The reversal at the surface of the profile $(0$ to $0.5 \mathrm{~m})$ results from undersaturation of kaolinite due to the dilute composition of rainfall and downward transport of any dissolved components from weathering. At the lower depths of the profile from approximately 3 to 7 meters, the precipitated kaolinite is a result of the broad reaction front of albite. As the primary mineral reaction fronts propagate downward, kaolinite accumulation occurs at greater depths. The developmental sequence of this pattern has obvious implications for the use of clay minerals in paleoclimate studies as well.

In addition to the mineral concentrations, the saturation state of kaolinite and the match to the aqueous $\mathrm{Al}$ and $\mathrm{SiO}_{2}(\mathrm{aq})$ provide additional constraints on the reaction rates determined here. Our model confirms the substantial degrees of kaolinite supersaturation suggested by the measured data for this terrace (Fig. 5) and all younger terraces (Fig. 13, White et al., this issue), even though we used the most soluble $\log K$ value for kaolinite reported in the literature. This degree of supersaturation ( $\log I A P / K \sim 2$ to 4 ) is perhaps unexpected, but consistent with other pore water studies (Steefel and Van Cappellen, 1990; White, 2002). Although XRD measurements did not show evidence for gibbsite and halloysite precipitation in the profiles, it is possible that the precipitation of a more soluble precursor mineral, followed by relatively rapid transformation to a more crystalline kaolinite, is responsible for the observed supersaturation and relatively slow kaolinite rate constant (e.g. Steefel and VanCappellen, 1990). According to this interpretation, halloysite or some other precursor with a solubility greater than kaolinite could be the actual phase controlling the pore water composition, as long as its conversion to kaolinite (as identified by XRD) is sufficiently rapid that the precursor cannot be observed in the profile. If this were the case, the rate constant for the phase with a halloysite composition would likely be about 4 orders of magnitude larger than the value we report for a kaolinite composition, since the solubility would be higher by that factor (thus producing an affinity term, or $\Delta \mathrm{G}$ driving force, that is 4 orders of magnitude smaller [see Equation 3a]).

The observation that the model somewhat overestimates the amount of kaolinite at shallow depths can be attributed to several factors, including the translocation of clays, seasonally low moisture contents, complexation of Al by organic matter and the effect of eolian input. The simplest explanation for the discrepancy between the model and the measured data is that clays from the top of the profile are translocated downward and flocculate as a result of humic acid concentrations (Kretzschmar et al., 1998). The amount of excess kaolinite at the surface is approximately equal to the discrepancy between the model and the measured abundances at $0.5 \mathrm{~m}$ depth, suggesting that some redistribution via translocation does occur. Examination of the orientation of clay films in the soil indicates that relatively little translocation has occurred at Santa Cruz, but the amount of translocation may vary among natural soils depending on hydrology, ionic strength and humic acid content of the pore water.

There are alternative explanations for the decline in clay abundance at the surface. For instance, if insufficient water is present, or if fractions of the total $\mathrm{Al}$ are forming strong complexes with organic ligands such that actual activities of $\mathrm{Al}^{3+}$ and $\mathrm{SiO}_{2}(\mathrm{aq})$ are less than our 
model predictions, then kaolinite precipitation would be suppressed to a greater extent than is suggested by the model. A strong correlation between DOC and total solute is also described by White et al. (this issue). Examples of processes which were found to suppress model kaolinite precipitation to the extent suggested by the data the are 1) complexation of $\mathrm{Al}^{3+}$ by dissolved organic matter at the surface followed by decomposition of organic matter at depth, 2) a steady input of eolian input with the composition of the protolith beach sand; and 3) a more soluble kaolinite composition such that kaolinite is undersaturated at the surface. Dust input reproduces the bulge in kaolinite and the reversals in the primary minerals, with no change to the calculated rate constants (Appendix 1). The effect from dust occurs because the constant supply of fresh mineral to the soil column maintains the location of the reaction fronts for albite, K-feldspar and kaolinite at the top of the profile (e.g. peak reaction rates occur at the very surface), while the constant addition of fresh material dilutes the kaolinite abundances resulting in a large bulge at the approximate depth of the argillic horizon. Complexation of $\mathrm{Al}$ by organic matter and the influx of dust may affect the shape of the profile at the surface, but will not dramatically change the calculated rate constants or the mechanisms. Although these are interesting results, their validity cannot be sufficiently evaluated at this time due to the lack of appropriate constraints, and moreover none of them required changes in the rate constants to match the observed data. We conclude that the peak accumulation of kaolinite and the development of the argillic horizon in soils is most likely a result of the overlap of the albite and K-feldspar weathering fronts coupled with undersaturation of kaolinite in dilute waters at the top of the profile.

\subsection{Effect of flow rates on weathering rates and weathering profiles}

It is possible that the amount of meteoric precipitation, and hence percolation rates, at SCT 5 have varied over the last few glacial-interglacial cycles. These cycles could have had a localized impact at Santa Cruz, in that the continental shelf was exposed for a distance of more than $20 \mathrm{~km}$ to the west of the current coast line during the last glacial maximum. This geographic shift could have impacted precipitation and possibly temperature. Our model uses the average net percolation flux determined from chloride mass balance estimates and thus represents an average over approximately the last 10 to 20 years (White et al., this issue). The uncertainties in the model values produced by uncertainty in the long-term flow rate are shown in Fig. 10 and are also discussed in Appendix 2. Fig. 10 shows the effect of a factor of \pm 1.5 variation in the flow rate and the increase in the rate of propagation of the weathering fronts at higher fluxes. Increased mass loss at higher flow rates occurs because the approach to equilibrium for the dissolving minerals is prolonged - at extremely high flow rates, reaction fronts become elongated, the approach to equilibrium is slower, and the gradient in saturation state and mineral abundance is steepened. Uncertainty in the flow rate does not transfer into uncertainty in the primary mineral dissolution rate constants because changes in the flow rate do not noticeably change the profile gradients, but rather increase the weathering advance rate.

\subsection{Secondary mineral precipitation as a control on primary mineral weathering}

Previous work has suggested that secondary mineral precipitation (Zhu et al., 2004; Godderis et al., 2006; Maher et al., 2006b) and re-crystallization are important processes in driving mineral-fluid reactions over long timescales (Steefel and Van Cappellen, 1990; Maher et al., 2004; Fantle and DePaolo, 2006, 2007). The nature of this relationship has not been explicitly demonstrated in a natural system due to insufficient data. As a result, kaolinite and other secondary minerals are often treated as passive by-products of primary mineral dissolution (e.g. precipitation rates are set equal to the primary mineral dissolution rates and possible supersaturation is not considered) as in the previous characterizations of weathering in the Santa Cruz terraces (White et al., 2008, this issue). Here we further refine the controls on profile 
evolution by documenting the importance of precipitation kinetics of secondary clays in controlling primary silicate weathering rates.

Although the shape of the kaolinite profile is affected by the reaction fronts of the dissolving minerals, kaolinite precipitation is critical for sustaining primary mineral dissolution. Fig. 11 shows the effects of a factor of 5 to 10 variation in the rate constant for kaolinite precipitation on its profile development in SCT 5, and the corresponding impact on the weathering profiles. For reference, the absence of kaolinite precipitation results in virtually no primary mineral dissolution because $\mathrm{Si}$ and, more importantly $\mathrm{Al}$, rapidly increase and pore waters saturate. It would require a flow rate of approximately $0.6 \mathrm{~m} / \mathrm{yr}$ (equal to or greater than annual precipitation) to dissolve the same amount of primary mineral as is dissolved when clay precipitation occurs. In other words, without the perturbation to the saturation state of the dissolving minerals provided by kaolinite, weathering would be minimal and the profile would advance very slowly.

Changes in the rate of kaolinite precipitation do not affect the primary mineral kinetic rate constants or weathering gradients. However, an increase in the rate constant removes weathering products from solution and therefore results in an increase in the weathering velocity of the primary minerals (Fig. 11). A factor of 10 decrease in the rate of kaolinite precipitation produces changes in the profiles comparable to the effect of a factor of 1.5 decrease in the flow rate (or about $100 \mathrm{ka}$ in profile development). The two variables are thus inversely correlated in the model (for the same fit to the data). Increasing kaolinite precipitation increases the total mass loss and the amount of mineral dissolved, but will not substantially change the gradients of the saturation state or weathering profiles over depth as the later are controlled by the intrinsic rate constants. For example, to fit the data at higher flow rates requires only a slower rate constant for kaolinite precipitation, but does not require appreciable changes to the primary mineral dissolution rates.. Therefore, uncertainty in the flow rate or soil $\mathrm{PCO}_{2}$ only affects the uncertainty in the kaolinite precipitation rate and not the primary mineral dissolution rates, as the profile gradients are fixed by relative mineral solubilities and rate constants. However, because kaolinite precipitation affects weathering profiles in the same manner as aqueous transport and soil $\mathrm{pH}$ or $\mathrm{PCO}_{2}$ (e.g. by influencing the reaction affinity of the dissolving phase), without the direct measurement of all of the parameters that perturb reaction affinity it would be difficult to distinguish their impact on soil profile evolution and total mass loss from weathering.

\subsection{Exporting experimental rate constants to natural systems}

A number of processes have been suggested as factors in the "dissolution rate conundrum" or the discrepancy between field and laboratory rates, including changes in the intrinsic reactivity of mineral surfaces (Maher et al., 2006b), limitations on reactive surface area in natural porous media (White and Peterson, 1990; White, 1995), limitations on flow and transport into low permeability zones in heterogeneous material (Clow and Drever, 1996; Malmstrom et al., 2004), slow precipitation of secondary minerals (Maher et al., 2006b), and transport rather than strict interface control of rates (Swoboda-Colberg and Drever, 1993; Clow and Drever, 1996; Steefel and Lichtner, 1998). Here we use geometric surface areas corrected for surface roughness, values that should be roughly equivalent to BET surface areas. As the protolith is composed of unconsolidated beach sands and the abundance of smectite is low, it is unlikely that substantial reductions in mineral surface areas are an important control on reaction rates at Santa Cruz. In terms of the hypothesis that physical heterogeneities could introduce an important effect, it should be noted that there are weak compositional variations in the protolith material as a function of depth and terrace age. However, these do not introduce substantial physical heterogeneities because the beach sands were well-sorted initially, and thus contain few if any clay lenses or other substantial grain-size variations that would act as barriers or conduits to flow. With very little evidence for either shielding of mineral surfaces or preferential flow, we suggest that the slower rate inferred for natural systems are the result of the non-linear approach to 
thermodynamic equilibrium and to the particular form in which reaction affinity is incorporated into the primary mineral dissolution rate laws. Our reference model, which used a simple linear TST description of mineral dissolution and precipitation, and considered measured mineral abundances, solute profiles and saturation states, still resulted in rate constants for mineral dissolution that were approximately 2 orders of magnitude slower than the experimental values (Table 4). We also found that factors that affect the approach to equilibrium, such as secondary mineral precipitation and flow rate, result in greater mass depletion, but minimal change in profile gradients (e.g. kinetic rate constants). Combined these observations suggest that the particular dependence on reaction affinity included in the overall rate law will be particularly important when experimental rate constants are exported to natural systems.

To address this observation, two additional rate law formulations were evaluated in addition to the linear TST rate law: a rate law that considers the effect of Al-inhibition (AIM), (Gautier et al., 1994; Oelkers and Schott, 1995), and a parallel rate law formulation (PRL), that explicitly considers non-linear close-to-equilibrium dissolution (Hellmann and Tisserand, 2006). Previous modeling work by Maher et al. (2006b) also noted that very slow clay precipitation and/or the precipitation of more soluble clay minerals resulted in close-to-equilibrium conditions and therefore laboratory-scale dissolution rate constants. Their suggestion could not be fully evaluated due to the lack of suitable constraints on both aqueous $\mathrm{Al}$ activities and clay mineral abundances at that particular site. The results from this study, which are constrained by the mineral abundances, the aqueous chemistry and thermodynamic saturation states, suggest that the majority of dissolution at Santa Cruz occurs close to equilibrium and as a result the inferred kinetic rate constants and the overall profile mass depletion are highly dependent on the particular form of the rate law, a finding similar to that of Sverdrup et al. (2002).

We considered three different formulations that vary in the values assigned to $n, m, \sigma$ and $\beta$. In order to evaluate the different rate laws, the albite and $\mathrm{K}$-feldspar rate constants were adjusted to match the gradient of the profiles. The major difference between kinetic models in terms of their ability to match the mineral abundance data occurred at low mineral abundances. As mineral surface area is depleted and bulk dissolution rates plummet, this results in greater degrees of undersaturation and therefore the PRL results in very sharp profiles at low mineral volumes. The Al-inhibition rate law (AIM) resulted in similar profiles to the linear TST reference model, but produced rate constants similar to experimental values.

Of the three rate laws, the L-TST rate law resulted in rate constants that are 2 orders of magnitude slower than the established laboratory rate constant of ca. $10^{-12.5}$ to $10^{-12.8} \mathrm{~mol} / \mathrm{m}^{2} / \mathrm{sec}$ based on an equivalent interpretation of experimental data obtained under far-from-equilibrium conditions (Palandri and Kharaka, 2004). In contrast, the two non-linear rate law formulations (PRL and AIM) resulted in rate constants that are comparable to laboratory values. For the PRL model, the temperature- and $\mathrm{pH}$-corrected laboratory rate constants of Hellmann and Tisserand (2006) required little adjustment from the experimental values. The "close-to-equilibrium" rate constant $\left(\mathrm{k}_{2}\right)$ determined in the laboratory by Hellmann and Tisserand (2006) is essentially the same as the value determined using the L-TST rate law formulation in the reference model (Fig. 9, and Table 4).

For the Al-inhibition model, the rate constants for both minerals are similar to experimental values $\left(10^{-12.8} \mathrm{~mol} / \mathrm{m}^{2} / \mathrm{sec}\right)$. The ability of the two nonlinear rate laws to describe both the mineral abundance profile and the porewater chemical data suggests that the noted discrepancy between laboratory and field rates may be a result of the affinity dependence of the reaction rates and the fact that the majority of dissolution occurs close-to-equilibrium. A parallel rate law like that developed by Hellmann and Tisserand (2006) minimizes the discrepancy between the laboratory and field rate constant because it results in a large range of $\Delta G_{r}$ values where the dissolution rates change slowly. The Al-inhibition model reduces the discrepancy because of the inhibitory effect of high aqueous $\mathrm{Al}$ concentrations (where the inhibition term $(\beta)$ 
is also associated with the approach to equilibrium) that suppress the destruction of a Si-rich precursor complex (cf. Gautier et al., 1994; Oelkers et al., 1994; Carroll and Knauss, 2005), although the Temkin coefficient of 3 (introducing a $1 / 3$ dependence on $\Delta \mathrm{G}$ ) also broadens the region in $\Delta G_{r}$ over which the rates goes from its maximum value to zero. Because the models were largely indistinguishable in their ability to match the aqueous and solid data, it is difficult to evaluate between the PRL and AIM models without further information. However, we note that the AIM provided a slightly better fit to the data than the PRL, where the latter caused a sharp step function to develop between low mineral concentrations and zero mineral concentrations as a result of the increase in the surface normalized rate at high undersaturations.

To further evaluate the alternative rate laws, it is worth noting that Beig and Luttge (2006), using a combination of high resolution imaging techniques (AFM, TEM and SEM) suggested that the bi-modal nature of many experimental data sets (cf. Burch et al., 1993; Taylor et al., 2000; Hellmann and Tisserand, 2006) was consistent with the "dissolution stepwave model" (Lasaga and Luttge, 2001, 2003; Luttge et al., 2003). Their experiments also suggested that the overall rates were strongly affected by the direction of the fluid evolution - from far from equilibrium to close-to-equilibrium or vise versa. Under far from equilibrium conditions, the opening of etch pits accelerates removal of material from within the etch pits and as a result of the propagation of steps away from the pit edges (Beig and Luttge, 2006). As the system approaches equilibrium, the surface defects are maintained. Conversely, "close-to-equilibrium" dissolution should be localized to surface defects generated as a result of comminution and cleaving (Beig and Luttge, 2006). If the reaction kinetics of silicate minerals (and other mineral classes) are characterized by this hysteresis effect, this may in part explain some of the wide variability in natural rates, and thus the apparent discrepancy between field and lab measurements.

Similarly, inhibition of the Si-rich precursor complex by aqueous Al may play a role in this observed behavior, although there is no clear linkage between the two effects, aside from their importance under near-equilibrium conditions. The Al-inhibition model is based on the experimental correlation between the $\log$ of $\mathrm{Al}$ concentration and $\log$ of the dissolution rate (Gautier et al., 1994; Oelkers et al., 1994; Oelkers, 2001). This observation, coupled with consideration of the surface chemistry led to the conclusion that the rates were controlled by the decomposition of an Al-deficient silica-rich surface precursor complex. It is likely significant that the ratio of the rate constants for the AIM and TST is approximately 0.007 , which is approximately the predicted value of $k / k_{\max }$ that is calculated from the $\mathrm{Al}$ concentrations measured at Santa Cruz (Fig. 12). Also shown in Fig. 12 are aqueous $\mathrm{SiO}_{2}$ and $\mathrm{Al}$ values corresponding to equilibrium with kaolinite calculated for an average SCT $5 \mathrm{pH}$ of 6 . The comparison between the predicted K-feldspar and albite dissolution rates when equilibrium with respect to kaolinite is assumed, versus the case indicated by the pore waters at Santa Cruz, demonstrates how supersaturation of kaolinite (presumably due to more soluble precursor minerals) plays a role in suppressing dissolution rates by allowing the albite to approach equilibrium. Most importantly, if this mechanism can be confirmed it may provide a means for scaling reaction rates between the field and the laboratory based on total $\mathrm{Al}$ concentrations and measured $\mathrm{pH}$.

\subsection{Positive feedback behavior in weathering profiles}

The precipitation of kaolinite provides a substantial driving force for dissolution of both Kfeldspar and albite. However, the relationship observed between albite and kaolinite differs from the relationship to K-feldspar in several important aspects. Fig. 13 shows the relationship between kaolinite and albite saturation states for the model simulations and the calculated pore water values. When kaolinite is at equilibrium, albite is substantially undersaturated, and even at high degrees of kaolinite supersaturation, albite is still undersaturated, although less substantially. The result of this condition is that as kaolinite precipitation increases (e.g. lower degrees of super saturation), the albite rate will increase as dissolution products are removed by kaolinite. This can 
also be observed in Fig. 4 where albite is dissolved from the bottom of the profile as kaolinite precipitation increases. The albite profile gradient becomes steeper over time, and the maximum reaction rate decreases as the weathering front broadens (assuming a semi-infinite profile). This relationship can also be described as an autocatalytic reaction, similar to that observed in other dissolution-precipitation experiments (Pina et al., 2000). An autocatalytic reaction would proceed at exponentially increasing rates unless a barrier was reached or some other process acts to inhibit the reaction. In the case of plagioclase weathering to kaolinite, this barrier is the total amount of available surface area. For example, increases in the rate of clay precipitation will enhance the rate of feldspar dissolution up to the maximum rate achievable far-from-equilibrium, consistent with surface reaction-control observable in the upper meters of the profile. At depth in the profile, lower kaolinite surface areas and slower nucleation rates (e.g. Fig. 5f, Fig 13) effectively inhibit the kaolinite precipitation rate. These limitations set important bounds on the reaction rates at the top and bottom of the profile, but are consistent with the observations of deep weathering within the profiles. This apparent autocatalytic relationship would vary as a function of flow rate (e.g. accumulation of cations), $\mathrm{pH}$ and the presence of other phases, all of which affect the reaction affinity at the leading edge of the reaction front.

Even if the precipitation of a more soluble precursor mineral such as halloysite (rather than kaolinite) was the rate controlling step (thus lowering the extent of supersaturation relative to the precursor phase and effectively increasing the rate constant), the same autocatalytic behavior would occur, as the system must follow the model reaction trajectory of Fig. 13 to be consistent with data constraints. It is therefore likely that this condition may occur in all multi-component systems and would strongly affect the most soluble of the dissolving phases. Weathering driven by clay precipitation may also explain observations of weathering in deep unsaturated zones (Maher et al., 2006a), deep-sea silicate sediments (Maher et al., 2006b; Wallmann et al., 2008), and groundwater systems (Kenoyer and Bowser, 1992; Zhu, 2005). The importance of secondary phases in moderating primary mineral dissolution rates has been pointed out in experimental studies (Alekseyev et al., 1997) and in field scale numerical simulations (Zhu et al., 2004; Godderis et al., 2006; Maher et al., 2006b). However, we suggest that this behavior is the result of a positive feedback process that occurs when the most soluble dissolving mineral is undersaturated and the principal precipitating phase is at equilibrium.

\section{CONCLUSION}

In order to understand how experimentally-determined rate constants and associated kinetic rate laws can be extrapolated to accurately portray the overall rates and process occurring in natural systems, we used a reactive transport model to fit several different measured constraints, including aqueous chemistry, mineral saturation state and solid elemental and mineral abundances. Rate constants were initially calculated for the primary dissolving minerals (albite and K-feldspar) and the dominant precipitating mineral (kaolinite) using a simple linear TST approach. The ability of this reference model to match the available data was compared to simulations that used experimentally-derived rate constants and the corresponding rate laws (AIM and PRL). Using a parallel rate law formulation (PRL), we calculated field scale rate constants consistent with those determined experimentally by Hellmann and Tisserand (2006). Similarly using a rate law formulation that depends on the activity of $\mathrm{Al}$ and a Temkin coefficient of 3 , we obtain dissolution rate constants within error of the laboratory values (as summarized in Palandri and Kharaka, 2004).

The intrinsic rate constant for the linear TST model was found to be 2 orders of magnitude smaller than the experimentally determined laboratory rate constant, even though the effect of kaolinite precipitation on the fluid saturation state was accounted for. However, when a nonlinear dependence on the approach to equilibrium was considered using alternative rate law formulations, we found that the calculated rate constants were within error of experimentally- 
determined rate constants for the same fit to the data achieved by the reference model. These results suggest that the discrepancy between experimentally and field-calculated rates is not purely a result of close-to-equilibrium dissolution in natural systems (White and Brantley, 2003), but depends on the particular form of the rate law as reaction rates approach equilibrium. The rate constants determined by best-fits to the field data are therefore consistent with experimental values only if rate laws that incorporate the slowing of dissolution rates close to equilibrium are considered.

The aqueous saturation state data for the dissolving minerals suggests dissolution in weathering profiles at a given depth begins very close-to-equilibrium and proceeds away from equilibrium over time. Together, these findings suggest that weathering at Santa Cruz occurs largely within the rate plateau defined by close-to-equilibrium dissolution. This observation would be consistent with the hypothesis presented by Beig and Luttge (2006) that if dissolution begins above a certain critical $\Delta G$, reaction will be controlled by surface retreat centered on limited surface defects. This process is therefore much slower than dissolution at values of $\Delta \mathrm{G}$ lower than the critical $\Delta G$ (more undersaturated), where etch-pits have an amplifying effect on the removal of material and the propagation of stepwave dissolution. The Al-inhibition model also does not require rate constants that are significantly different from those determined in the laboratory. Here, the effect of high $\mathrm{Al}$ concentrations resulting from clay supersaturation results in inhibition of the dissolution rates, while the Temkin coefficient of 3 broadens the range in $\Delta \mathrm{G}$ over which the transition from a maximum dissolution rate (the so-called "dissolution plateau") to equilibrium (where the rate $=0$ ) is made. Al-inhibition provides a suitable explanation for the apparent suppression of dissolution rates in natural systems, particularly when coupled with sluggish clay precipitation, and if verified, may present a means of scaling laboratory rates using measured $\mathrm{pH}$ and $\mathrm{Al}$ concentrations as suggested by Fig. 12.

It is commonly assumed that mass depletion in a profile is a function of the dissolution rate of the primary minerals, the flow rate and time. However, the present analysis suggests that the propagation of a weathering front is also controlled by the rate of secondary mineral precipitation. Therefore, weathering profiles are not purely transport-limited or time dependent, but also depend on the rate of secondary mineral formation. This work suggests that the nature of the transition from $\Delta G_{r}=0$ to $\Delta G_{r}<0$ will determine the rate at which the weathering profile advances. The factor - flow, precipitation, vegetation, or other - that has the greatest influence on the $\Delta G_{r}$ of the dissolving minerals will be the predominant control on weathering rates in a particular system.

\section{Appendix 1. Model sensitivities and limitations}

\subsection{Effect of mass loss or mass gain via eolian deposition or erosion on observed profiles and reaction rates}

\section{2 .}

The sharp reversal in the observed primary mineral abundances in the upper 0.5 meters of the terrace 5 profile is most likely a result of dust deposition (Fig. 4). This deposition could have been continuous over the duration of profile development, or may have occurred episodically when sea level was substantially lower. To simulate the gross effects of dust deposition, a continuous supply of dust was added to the top of the column at the composition of the protolith. The depositional flux was $21.5 \mathrm{~g} / \mathrm{m}^{2} / \mathrm{yr}$, which is the average value computed for eolian fluxes to coastal southern California (Muhs et al., 2007). This represents the maximum likely dust flux as the Santa Cruz terraces are located close to the ocean and therefore probably receive a much lower flux of dust than the southern coastal areas that receive dust from the Mojave Desert seasonally (Muhs et al., 2007). Profiles corresponding to this dust input using the rate constants from the best-fit TST model are shown in Fig. 14. Incorporating a dust flux does not appreciably change the fit to the data but does result in a more close approximation of the argillic horizon and 
simulates the reversal at the top of the profiles. The vertical depth of the model K-feldspar profile is relatively unaffected, while there is slightly more depletion in the albite profile at shallow depth. We conclude that, over the timescale considered here, dust is unlikely to affect the observed weathering rates within error of the values presented in Table 4. Our analysis also suggests that dust input may play a role in the distinct bulge in clay abundance associated with the argillic horizon.

\subsection{Effect of variations in soil $\mathrm{PCO}_{2}$}

Although soil gas concentrations were measured and soil water $\mathrm{pH}$ was calculated from the alkalinity and measured $\mathrm{PCO}_{2}$, the model $\mathrm{pH}$ values differed slightly from the measured. In order to understand the sensitivity of our results to the effect of $\mathrm{PCO}_{2}$ (and $\mathrm{pH}$ ) on model results, we considered a range of $\mathrm{PCO}_{2}$ concentrations spanning an order of magnitude on either side of the actual measured value of 0.1 bars (Fig. 15). As expected based on other sensitivity analyses, the effect of increased $\mathrm{PCO}_{2}$ is increase the weathering advance rate similar to the effects observed for increased flow, increased duration of weathering and increased kaolinite precipitation rate. In order to fit the data at elevated $\mathrm{PCO}_{2}$ required that the rate of kaolinite precipitation be reduced by two orders of magnitude (and increased by a corresponding magnitude at lower $\mathrm{PCO}_{2}$ and elevated $\mathrm{pH}$ ). Therefore, even if there is substantial (e.g. order of magnitude) error in the measured soil $\mathrm{PCO}_{2}$ values, this does not introduce additional error into the dissolution rate of primary minerals, but does result in uncertainty in the rate of secondary mineral precipitation.

\subsection{Effect of kaolinite solubility and intitial protolith abundance on kaolinite rates}

Kaolinite solubilities $\left(25^{\circ} \mathrm{C}\right)$ reported in the literature range over several orders of magnitude. This may be due to the presence of more soluble precursor minerals such as halloysite or allophane in the phases used for the experiments, small amounts of secondary mineral precipitation during experiments, or errors in measuring aqueous species at dilute concentrations. The value chosen in the simulations was measured by Yang and Steefel (2008), and is similar to the value determined by Nagy et al. (1991). This value is $0.8 \log$ units more soluble than the value in the EQ3/EQ6 database (Wolery et al., 1990), but closer to values measured in aquifers and low-temperature weathering environments (e.g. Grimaud et al., 1990). This representation would also be consistent with the fine-grained and poorly crystalline nature of the kaolinite at Santa Cruz. To understand how the uncertainty in solubility would affect our results, different solubilities from the literature were evaluated. A less soluble kaolinite composition (approximately 1 order of magnitude change in the $\log K$ value) results in more kaolinite precpitation and more weathering of albite and K-feldspar (Figs. 13, 16). The effect of solubility of kaolinite is also similar to those demonstrated for flow and time and precipitation rate as expected, and according to our hypothesis that reaction affinity is the critical factor controlling the position and geometry of the weathering fronts. The range in log $\mathrm{K}$ values means that we can only constrain the rate constant of kaolinite to within a range dictated by the uncertainty in the kaolinite solubility - about 2 orders of magnitude - and highlights our relative lack of knowledge regarding the aspects of secondary mineral precipitation in many systems.

There is also some uncertainty in the initial abundance of kaolinite in the profile. The effect of this uncertainty is shown in Fig. 16. We assume that kaolinite precipitates on pre-existing kaolinite surface sites, which may be an over simplification of the kaolinite nucleation processes. This assumption also introduces further uncertainty into the kaolinite rate constant, as the surface area features prominently in the overall rate law. This uncertainty in the initial abundance (or total initial surface area) affects only the kaolinite rates and not the albite and K-feldspar rate constants. 


\subsection{Parameter sensitivity and covariance}

Model sensitivity and parameter correlation was evaluated using PEST (Doherty, 2004). This program operates by minimizing the sum-squared difference between the measured constraints and model output values and has been used previously in conjunction with CrunchFlow (Giambalvo et al., 2002; Steefel et al., 2003). The parameters that were allowed to vary in PEST were the percolation flux, kaolinite precipitation rate constant, and the K-feldspar and albite dissolution rate constants. Each parameter was given a tolerance in PEST: the flow rate was allowed to vary by a factor of \pm 2 , which was greater than the maximum variability observed between the five terraces. Kaolinite rates were allowed to vary by 2 orders of magnitude, and dissolution rates for primary minerals by 1 . The measured constraints consisted of the mineral abundance profiles for K-feldspar, albite and kaolinite and the aqueous $\mathrm{Al}^{3+}$ and $\mathrm{SiO}_{2}$ (aq) concentrations. For K-feldspar and albite the reversals in the upper meter due to dust accumulation were removed and the measured values were set to $0.01 \mathrm{vol} \%$ and $0.1 \mathrm{vol} \%$ respectively. The aqueous concentrations in $\mathrm{mol} / \mathrm{L}$ were weighted such that they were given equal importance to the volumetric mineral abundances. The PEST simulation was run only for the simple TST model.

The PEST optimizations that used both the solid and aqueous chemistry as constraints suggests an optimal flow rate of $0.07 \pm 0.05 \mathrm{~m} / \mathrm{yr}$ (compared to the chloride mass balance calculation of $0.088 \mathrm{~m} / \mathrm{yr}$ ) and within the range suggested by the variability of the measured flow rates at the individual terraces. This uncertainty in flow rates corresponds to uncertainty in the kaolinite rate of $10^{-19 \pm 0.85} \mathrm{~mol} / \mathrm{m}^{2} / \mathrm{sec}$. The values for the dissolution rate constants obtained using PEST were nearly identical to those determined based on the measured flow rate and a subjective fit to the data. PEST was also used to evaluate the correlation between variables and the sensitivity of the model parameters. Table 5 shows the correlation matrix describing the interdependence between dissolution rates, flow rates and secondary mineral precipitation. The strongest inverse correlation is between the log of the kaolinite rate and the flow rate $(-0.99)$. Conversely, the albite profile is slow to approach equilibrium, therefore the rate shows a weak correlation with flow (0.34) and only a weak inverse correlation with kaolinite precipitation (0.37 ) and K-feldspar dissolution (-0.61). This is in contrast to our sensitivity analysis of individual parameters (flow, $\mathrm{pH}$, solubility and initial volume fraction) where we found that all of the uncertainty was related to the description of kaolinite precpitation. K-feldspar is more strongly correlated with kaolinite precipitation because of its lower solubility. The correlation coefficients by reverse parameter estimation are useful for understanding the reaction network in a weathering environment and provide a means of understanding the interdependence of the different model parameters and therefore the likelihood that they can be uniquely determined. This suite of values suggested by the PEST simulations resulted in a nearly identical fit to the data as that provided subjectively. As suggested previously, the strong inverse correlation between the flow rate and kaolinite precipitation rate suggests that in the absence of information about the flow rate, it would be difficult to uniquely determine the rate of secondary mineral precipitation unless specific isotope tracers are used to provide further constraints.

\section{Appendix 2. Model limitations and assumptions}

We did not consider time-dependent increases in surface roughness, seasonal and millennial moisture fluctuations, preferential flow/heterogeneity, occlusion of surfaces by secondary minerals, and the role of biological activity in altering the elemental fluxes. We recognize the importance of these weathering processes, but we either did not have sufficient constraints to include them, or identified them through preliminary calculations as minor effects relative to the main processes mentioned above. These effects were judged to be minor in the Santa Cruz chronosequences, but may be nonetheless more important at other weathering sites. 
In addition to the complication presented by the range in reported equilibrium constants for kaolinite, the model formulation presented here also cannot account for many of the complexities that are likely to affect clay precipitation in natural systems. These include: clay illuviation and flocculation (most likely important in the upper $50 \mathrm{~cm}$ ), epitaxial precipitation on primary mineral grains, preferential flow and reduced permeability in clay-rich zones, the interfacial energy barrier associated with nucleation, and the effect of wetting and drying cycles. Epitaxial clay precipitation has been suggested as one mechanism for limiting the reactive surface areas of the dissolving minerals. We did not find evidence for significant shielding of mineral surfaces, although secondary mineral accumulation on primary mineral grains and the presence of biofilms may introduce some uncertainty in to the surface areas and therefore the calculated rate constants. A decrease in the permeability and the development of preferential flow features is likely to occur with increasing clay contents and weathering age. A more detailed discussion of hydrologic variability will be presented in a subsequent paper. These developments are likely to impact the hydrology of the system, resulting in either lower net infiltration fluxes, or zones of immobile fluid respectively. In either case, stagnating pore fluid results in zones with markedly different chemistry. With respect to the precipitation rate of kaolinite determined here, this parameter is subject to uncertainty resulting from limitations in our knowledge of the solubility and the operative rate law for kaolinite precipitation (cf. Yang and Steefel, 2008), and the extent to which kaolinite forms partly or wholly from a more soluble precursor phase such as halloysite (Steefel and Van Cappellen, 1990). The primary dissolution rate constants are subject to less uncertainty because the gradient in the profiles uniquely results from a combination of the relative differences in mineral solubility and the intrinsic mineral dissolution rates. Even though several different rate laws formulations were evaluated, they all result in similar rate constants and overall rates in the particular saturation state region suggested by the measured pore waters. The major uncertainties therefore result from the assumed surface area and small departures from the theoretical solubilities used in the model.

\section{Acknowledgments:}

The authors would like to acknowledge the A.E., E. Bolton, Y. Godderis and B. Fritz for their helpful comments and suggestions. This work was supported in part by the Director, Office of Science, Office of Basic Energy Sciences, Division of Chemical Sciences, Geosciences, and Biosciences of the U.S. Department of Energy under Contract No. DE-AC02-05CH11231 to Lawrence Berkeley National Laboratory.

\section{References}

Aagaard P. and Helgeson H. C. (1982) Thermodynamic and Kinetic Constraints on ReactionRates among Minerals and Aqueous-Solutions .1. Theoretical Considerations. Am. J. Sci. 282(3), 237-285.

Alekseyev V. A., Medvedeva L. S., Prisyagina N. I., Meshalkin S. S., and Balabin A. I. (1997) Change in the dissolution rates of alkali feldspars as a result of secondary mineral precipitation and approach to equilibrium. Geochim. Cosmochim. Acta 61(6), 1125-1142.

Anderson R. S., Densmore A. L., and Ellis M. A. (1999) The generation and degradation of marine terraces. Basin Research 11, 7-19.

Arnorsson S. and Stefansson A. (1999) Assessment of feldspar solubility constants in water in the range 0 degrees to 350 degrees C at vapor saturation pressures. Am. J. Sci. 299(3), 173209.

Beig M. S. and Luttge A. (2006) Albite dissolution kinetics as a function of distance from equilibrium: Implications for natural feldspar weathering. Geochim. Cosmochim. Acta 70(6), 1402-1420. 
Bolton E. W., Berner R. A., and Petsch S. T. (2006) The weathering of sedimentary organic matter as a control on atmospheric O-2: II. Theoretical modeling. Am. J. Sci. 306(8), 575615.

Borden D. and Giese R. F. (2001) Baseline studies of The Clay Minerals Society Source Clays: Cation exchange capacity measurements by the ammonia-electrode method. Clay Clay Min. 49(5), 444-445.

Burch T. E., Nagy K. L., and Lasaga A. C. (1993) Free-Energy Dependence of Albite Dissolution Kinetics at 80-Degrees-C and Ph 8.8. Chemical Geology 105(1-3), 137-162.

Cama J., Ganor J., Ayora C., and Lasaga C. A. (2000) Smectite dissolution kinetics at 80 degrees $\mathrm{C}$ and $\mathrm{pH}$ 8.8. Geochim. Cosmochim. Acta 64(15), 2701-2717.

Cama J., Metz V., and Ganor J. (2002) The effect of $\mathrm{pH}$ and temperature on kaolinite dissolution rate under acidic conditions. Geochim. Cosmochim. Acta 66(22), 3913-3926.

Carroll S. and Knauss K. G. (2005) Dependence of labradorite dissolution kinetics on CO2(aq), $\mathrm{Al}(\mathrm{aq})$, and temperature. Chemical Geology 217, 213-225.

Casey W. H., Westrich H. R., Banfield J. F., Ferruzzi G., and Arnold G. W. (1993) Leaching and Reconstruction at the Surfaces of Dissolving Chain-Silicate Minerals. Nature 366(6452), 253-256.

Cerling T. E. (1984) The Stable Isotopic Composition of Modern Soil Carbonate and Its Relationship to Climate. Earth and Planetary Science Letters 71(2), 229-240.

Clow D. W. and Drever J. I. (1996) Weathering rates as a function of flow through an alpine soil. Chemical Geology 132(1-4), 131-141.

Coppin F., Berger G., Bauer A., Castet S., and Loubet M. (2002) Sorption of lanthanides on smectite and kaolinite. Chemical Geology 182(1), 57-68.

Devidal J. L., Dandurand J. L., and Gout R. (1996) Gibbs free energy of formation of kaolinite from solubility measurement in basic solution between 60 and 170 degrees C. Geochim. Cosmochim. Acta 60(4), 553-564.

Doherty J. (2004) PEST - Model Independent Parameter Estimation, User's Manual. Watermark Numerical Computing. (http://www.sspa.com/pest),

Eberl D. D. (2003) User's Guide to ROCKJOCK--A program for determining quantitative mineralogy from powder x-ray diffraction data. U. S. Geological Survey Open File Report 03-78.

Fantle M. S. and DePaolo D. J. (2006) Sr isotopes and pore fluid chemistry in carbonate sediment of the Ontong Java Plateau: Calcite recrystallization rates and evidence for a rapid rise in seawater Mg over the last 10 million years. Geochimica Et Cosmochimica Acta 70(15), 3883-3904.

Fantle M. S. and DePaolo D. J. (2007) Ca isotopes in carbonate sediment and pore fluid from ODP Site 807A: The Ca2+(aq)-calcite equilibrium fractionation factor and calcite recrystallization rates in Pleistocene sediments. Geochimica Et Cosmochimica Acta 71(10), 2524-2546.

Gautier J. M., Oelkers E. H., and Schott J. (1994) Experimental-Study of K-Feldspar Dissolution Rates as a Function of Chemical Affinity at 150-Degrees-C and Ph-9. Geochim. Cosmochim. Acta 58(21), 4549-4560.

Giambalvo E. R., Steefel C. I., Fisher A. T., Rosenberg N. D., and Wheat C. G. (2002) Effect of fluid-sediment reaction on hydrothermal fluxes of major elements, eastern flank of the Juan de Fuca Ridge. Geochim. Cosmochim. Acta 66(10), 1739-1757.

Godderis Y., Francois L. M., Probst A., Schott J., Moncoulon D., Labat D., and Viville D. (2006) Modelling weathering processes at the catchment scale: The WITCH numerical model. Geochim. Cosmochim. Acta 70(5), 1128-1147.

Grimaud D., Beaucaire C., and Michard G. (1990) Modeling of the Evolution of Ground Waters in a Granite System at Low-Temperature - the Stripa Ground Waters, Sweden. Applied Geochemistry 5(4), 515-525. 
Hellmann R. (1994) The Albite Water-System .1. the Kinetics of Dissolution as a Function of Ph at 100, 200, and 300-Degrees-C (Vol 58, Pg 595, 1994). Geochim. Cosmochim. Acta 58(23), 5369-5369.

Hellmann R. and Tisserand D. (2006) Dissolution kinetics as a function of the Gibbs free energy of reaction: An experimental study based on albite feldspar. Geochim. Cosmochim. Acta 70(2), 364-383.

Hobson W. A. and Dahlgren R. A. (1998) A quanitative study of pedogenesis in California vernal pool wetlands. In Quantifying Soil Hydromorphology, SSSA Spec. Publiccation, Vol. 54 (ed. M. C. Rabenhorst, J. C. Bell, and P. A. McDaniel), pp. 107127. Soil Science Soc. Am.

Hopkins D. G. and Franzen D. W. (2003) Argillic horizons in stratified drift: Luverne end moraine, eastern North Dakota. Soil Science Society of America Journal 67(6), 17901796.

Huertas F. J., Chou L., and Wollast R. (1999) Mechanism of kaolinite dissolution at room temperature and pressure Part II: Kinetic study. Geochim. Cosmochim. Acta 63(19-20), 3261-3275.

Kenoyer G. J. and Bowser C. J. (1992) Groundwater Chemical Evolution in a Sandy Silicate Aquifer in Northern Wisconsin .2. Reaction Modeling. Water Resour. Res. 28(2), 591600.

Kohler S. J., Bosbach D., and Oelkers E. H. (2005) Do clay mineral dissolution rates reach steady state? Geochim. Cosmochim. Acta 69(8), 1997-2006.

Kohler S. J., Dufaud F., and Oelkers E. H. (2003) An experimental study of illite dissolution kinetics as a function of $\mathrm{pH}$ from 1.4 to 12.4 and temperature from 5 to 50 degrees $\mathrm{C}$. Geochim. Cosmochim. Acta 67(19), 3583-3594.

Kretzschmar R., Holthoff H., and Sticher H. (1998) Influence of pH and humic acid on coagulation kinetics of kaolinite: A dynamic light scattering study. Journal of Colloid and Interface Science 202(1), 95-103.

Lasaga A. C. (1984) Chemical-Kinetics Of Water-Rock Interactions. Journal Of Geophysical Research 89(NB6), 4009-4025.

Lasaga A. C. and Luttge A. (2001) Variation of crystal dissolution rate based on a dissolution stepwave model. Science 291(5512), 2400-2404.

Lasaga A. C. and Luttge A. (2003) A model for crystal dissolution. Eur. J. Mineral. 15(4), 603615.

Lichtner P. C. (1993) Scaling properites of time-space kinetic mass transport equations and the local equilibrium limit. Am. J. Sci. 293, 257-296.

Luttge A., Winkler U., and Lasaga A. C. (2003) Interferometric study of the dolomite dissolution: A new conceptual model for mineral dissolution. Geochim. Cosmochim. Acta 67(6), 1099-1116.

Ma C. and Eggleton R. A. (1999) Cation exchange capacity of kaolinite. Clay Clay Min. 47(2), 174-180.

Maher K., DePaolo D. J., and Christensen J. N. (2006a) U-Sr isotopic speedometer: flow and chemical weathering in aquifers. Geochim. Cosmochim. Acta 70(17), 4417-4435.

Maher K., DePaolo D. J., and Lin J. C.-L. (2004) Rates of silicate dissolution in deep-sea sediment: In situ measurement using ${ }^{234} \mathrm{U} /{ }^{238} \mathrm{U}$ of pore fluids. Geochim. Cosmochim. Acta.

Maher K., Steefel C. I., DePaolo D. J., and Viani B. E. (2006b) The mineral dissolution rate conundrum: Insights from reactive transport modeling of $U$ isotopes and pore fluid chemistry in marine sediments. Geochim. Cosmochim. Acta 70(2), 337-363.

Malmstrom M. E., Destouni G., and Martinet P. (2004) Modeling expected solute concentration in randomly heterogeneous flow systems with multicomponent reactions. Environmental Science \& Technology 38(9), 2673-2679. 
Michalopoulos P. and Aller R. C. (1995) Rapid Clay Mineral Formation in Amazon Delta Sediments - Reverse Weathering and Oceanic Elemental Cycles. Science 270(5236), 614617.

Muhs D. R., Budahn J., Reheis M., Beann J., Skipp G., and FIsher E. (2007) Airborne dust transport to the eastern Pacific Ocean off southern California: Evidence from San Clemente Island Journal of Geophysical Research-Atmospheres 112(D13203), 17.

Nagy K. L. (1995) Dissolution and precipitation kinetics of sheet silicates. In Chemical Weathering Rates of Silicate Minerals, Vol. 31, pp. 173-233.

Nagy K. L., Blum A. E., and Lasaga A. C. (1991) Dissolution and Precipitation Kinetics of Kaolinite at 80-Degrees-C and $\mathrm{Ph} 3$ - the Dependence on Solution Saturation State. Am. J. Sci. 291(7), 649-686.

Nagy K. L. and Lasaga A. C. (1992) Dissolution and Precipitation Kinetics of Gibbsite at 80Degrees-C and Ph-3 - the Dependence on Solution Saturation State. Geochim. Cosmochim. Acta 56(8), 3093-3111.

Nagy K. L. and Lasaga A. C. (1993) Simultaneous Precipitation Kinetics of Kaolinite and Gibbsite at 80-Degrees-C and Ph-3. Geochim. Cosmochim. Acta 57(17), 4329-4335.

Oelkers E. H. (2001) General kinetic description of multioxide silicate mineral and glass dissolution. Geochim. Cosmochim. Acta 65(21), 3703-3719.

Oelkers E. H. and Schott J. (1995) Experimental study of anorthite dissolution and the relative mechanism of feldspar hydrolysis. Geochim. Cosmochim. Acta 59(24), 5039-5053.

Oelkers E. H., Schott J., and Devidal J. L. (1994) The effect of aluminum, pH, and chemical affinity on the rates of aluminosilicate dissolution reactions. Geochim. Cosmochim. Acta 58(9), 2011-2024.

Ortoleva P., Chadam J., Merino E., and Sen A. (1987) Geochemical Self-Organization .2. The reactive-infiltration instability. Am. J. Sci. 287(10), 1008-1040.

Palandri J. L. and Kharaka Y. K. (2004) A compilation of rate parameters of water-mineral interaction kinetics for application to geochemical modeling. US Geological Survey Open File Report, 2004-1068.

Parkhurst D. L. and Appelo C. A. J. (1999) User's guide to PHREEQC (version 2)—OA Computer Program for the Speciation,

Batch Reaction, One Dimensional Transport, and Inverse Geochemical Calculations. U.S. Geol. Sur. Water Invest. Rep, 99.

Perg L. A., Anderson R. S., and Finkel R. C. (2001) Use of a new 10Be and 26Al inventory method to date marinie terraces, Santa Cruz, California, USA. Geology 29, 879-882.

Perillo C. A., Gupta S. C., Nater E. A., and Moncrief J. F. (1999) Prevalence and initiation of preferential flow paths in a sandy loam with argillic horizon. Geoderma 89(3-4), 307331.

Pina C. M., Frenandez-Diaz L., Prieto M., and Putnis A. (2000) In situ atomic force microscope observations of a dissolution- crystallisation reaction: The phosgenite- cerussite transformation. Geochimica et Cosmochimica Acta 64(2), 215-221.

Price J. R., Velbel M. A., and Patino L. C. (2005) Rates and time scales of clay-mineral formation by weathering in saprolitic regoliths of the southern Appalachians from geochemical mass balance. Geological Society of America Bulletin 117(5-6), 783-794.

Steefel C. I. (2001) Software for modeling multicomponent, multidimensional reactive transport. Lawrence Livermore National Laboratory, UCRL-MA-143182.

Steefel C. I., Carroll S., Zhao P. H., and Roberts S. (2003) Cesium migration in Hanford sediment: a multisite cation exchange model based on laboratory transport experiments. Journal of Contaminant Hydrology 67(1-4), 219-246.

Steefel C. I. and Lasaga A. C. (1994) A Coupled Model for Transport of Multiple ChemicalSpecies and Kinetic Precipitation Dissolution Reactions with Application to Reactive Flow in Single-Phase Hydrothermal Systems. Am. J. Sci. 294(5), 529-592. 
Steefel C. I. and Lichtner P. C. (1998) Multicomponent reactive transport in discrete fractures: I. Controls on reaction front geometry. Journal Of Hydrology 209(1-4), 186-199.

Steefel C. I. and Van Cappellen P. (1990) A New Kinetic Approach to Modeling Water-Rock Interaction - the Role of Nucleation, Precursors, and Ostwald Ripening. Geochim. Cosmochim. Acta 54(10), 2657-2677.

Steefel C. I. and VanCappellen P. (1990) A New Kinetic Approach to Modeling Water-Rock Interaction - the Role of Nucleation, Precursors, and Ostwald Ripening. Geochim. Cosmochim. Acta 54(10), 2657-2677.

Steefel C. I. and Yabusaki S. B. (1996) OS3D/GIMRT, Software for multicomponentmultidimensional reactive transport: User's Manual and Programmer's Guide. Pacific Northwest National Laboratory, PNNL-11166.

Stefansson A. and Gislason S. R. (2001) Chemical weathering of basalts, Southwest Iceland: Effect of rock crystallinity and secondary minerals on chemical fluxes to the ocean. Am. J. Sci. 301(6), 513-556.

Stonestrom D. A., White A. F., and Akstin K. C. (1998) Determining rates of chemical weathering in soils - solute transport versus profile evolution. Journal of Hydrology 209(1-4), 331-345.

Sverdrup H., Hagen-Thorn A., Holmqvist J., Wallman P., Warfinge P., Walse C., and Alveteg M. (2002) Biogeochemical processes and mechanisms. In Developing principles and models for sustainable forestry in Sweden (ed. H. Sverdrup and I. Stjernquist), pp. 91-196. Kluwer Academic Publishers, Dordrecht.

Swoboda-Colberg N. G. and Drever J. I. (1993) Mineral Dissolution Rates in Plot-Scale Field and Laboratory Experiments. Chemical Geology 105(1-3), 51-69.

Taylor A. S., Blum J. D., and Lasaga A. C. (2000) The dependence of labradorite dissolution and $\mathrm{Sr}$ isotope release rates on solution saturation state. Geochim. Cosmochim. Acta 64(14), 2389-2400.

USDA. (1999) Soil Taxonomy: A basis system of soil classification for making and interpreting soil surveys. In Agricultural Handbook (ed. S. S. Staff). Soil Conservation Service, USDA, U.S. Gov. Print Office, Washington D.C.

Wallmann K., Aloisi G., Tischenko P., Pavlova G., Greinert J., Kutterolf S., and Eisenhauer A. (2008) Silicate weathering in anoxic marine sediments. Geochim. Cosmochim. $\operatorname{Acta}(3067-3090)$.

West A. J., Galy A., and Bickle M. (2005) Tectonic and climatic controls on silicate weathering. Earth Planet. Sci. Lett. 235(1-2), 211-228.

White A. F. (1995) Chemical weathering rates of silicate minerals is soils. In Chemical Weathering Rates of Silicate Minerals, Vol. 31, pp. 407-461. Mineralogical Society of America.

White A. F. (2002) Determining mineral weathering rates based on solid and solute weathering gradients and velocities: application to biotite weathering in saprolites. Chemical Geology 190(1-4), 69-89.

White A. F. and Blum A. E. (1995) Effects of Climate on Chemical-Weathering in Watersheds. Geochim. Cosmochim. Acta 59(9), 1729-1747.

White A. F., Blum A. E., Schulz M. S., Vivit D. V., Stonestrom D. A., Larsen M., Murphy S. F., and Eberl D. (1998) Chemical weathering in a tropical watershed, Luquillo mountains, Puerto Rico: I. Long-term versus short-term weathering fluxes. Geochim. Cosmochim. Acta 62(2), 209-226.

White A. F. and Brantley S. L. (2003) The effect of time on the weathering of silicate minerals: why do weathering rates differ in the laboratory and field? Chemical Geology 202(3-4), 479-506. 
White A. F., Chuma N. J., and Goff F. (1992) Mass-Transfer Constraints on the Chemical Evolution of an Active Hydrothermal System, Valles-Caldera, New-Mexico. Journal of Volcanology and Geothermal Research 49(3-4), 233-253.

White A. F. and Peterson M. L. (1990) Role of reactive-surface-area characterization in geochemical kinetic models. ACS Symposium Series 416, 461-475.

White A. F., Schulz M. S., Lowenstern J. B., Vivit D. V., and Bullen T. D. (2005a) The ubiquitous nature of accessory calcite in granitoid rocks: Implications for weathering, solute evolution, and petrogenesis. Geochim. Cosmochim. Acta 69(6), 1455-1471.

White A. F., Schulz M. S., Stonestrom D. A., Vivit D. V., Fitzpatrick J., Bullen T., Maher K., and Blum A. E. (in review) Chemical Weathering of a Marine Terrace Chronosequence, Santa Cruz, California II: Controls on Solute Fluxes and Comparisons of Long-term and Contemporary Mineral Weathering rates. Geochim. Cosmochim. Acta.

White A. F., Schulz M. S., Stonestrom D. A., Vivit D. V., Fitzpatrick J., Bullen T., Maher K., and Blum A. E. (submitted) Chemical Weathering of a Marine Terrace Chronosequence, Santa Cruz, California II: Controls on Solute Fluxes and Comparisons of Long-term and Contemporary Mineral Weathering rates. Geochim. Cosmochim. Acta.

White A. F., Schulz M. S., Vivit D. V., Blum A., Stonestrom D. A., and Anderson S. P. (2008) Chemical Weathering of a Marine Terrace Chronosequence, Santa Cruz, California I: Interpreting the Long-Term Controls on Chemical Weathering based on Spatial and Temporal Element and Mineral Distributions Geochimica Et Cosmochimica Acta 72(1), 36-68.

White A. F., Schulz M. S., Vivit D. V., Blum A. E., Stonestrom D. A., and Harden J. W. (2005b) Chemical weathering rates of a soil chronosequence on granitic alluvium: III. Hydrochemical evolution and contemporary solute fluxes and rates. Geochim. Cosmochim. Acta 69(8), 1975-1996.

Wolery T. J., Jackson K. J., Bourcier W. L., Bruton C. J., Viani B. E., Knauss K. G., and Delany J. M. (1990) Current status of the EQ3/6 software package for geochemical modeling. ACS Symposium Series 416, 104-116.

Yang L. and Steefel C. I. (2008) Kaolinite dissolution and precipitation kinetics at 22 degrees C and $\mathrm{pH}$ 4. Geochim. Cosmochim. Acta 72(1), 99-116.

Yokoyama T. and Banfield J. F. (2002) Direct determinations of the rates of rhyolite dissolution and clay formation over 52,000 years and comparison with laboratory measurements Geochim. Cosmochim. Acta 66(15), 2665-2681.

Zhu C. (2005) In situ feldspar dissolution rates in an aquifer. Geochim. Cosmochim. Acta 69(6), $1435-1453$.

Zhu C., Blum A. E., and Veblen D. R. (2004) Feldspar dissolution rates and clay precipitation in the Navajo aquifer at Black Mesa, Arizona, USA. In Proceedings of the Eleventh International Symposium on Water-Rock Interaction WRI-11, Vol. 2 (ed. R. B. Wanty and R. R. I. Seal), pp. 895-899. A.A. Balkema.

Zhu C., Veblen D. R., Blum A. E., and Chipera S. J. (2006) Naturally weathered feldspar surfaces in the Navajo Sandstone aquifer, Black Mesa, Arizona: Electron microscopic characterization Geochim. Cosmochim. Acta 70, 4600-4616. 
Table 1: Description of thermodynamic data, initial mineral abundances and specific surface areas used in model formulation.

\begin{tabular}{|c|c|c|c|c|}
\hline Mineral & Mineral Formula & $\begin{array}{l}\log \mathrm{K} \\
\left(25^{\circ} \mathrm{C}\right)\end{array}$ & $\begin{array}{c}\text { Initial } \\
\text { Conc. } \\
\left(\mathbf{m}^{3} / \mathbf{m}^{3}\right)\end{array}$ & $\begin{array}{c}\text { Surface } \\
\text { Area } \\
\left(\mathrm{m}^{2} / \mathrm{g}\right) \\
\end{array}$ \\
\hline \multicolumn{5}{|c|}{ Model 1: End-member compositions } \\
\hline Albite & $\mathrm{NaAlSi}_{3} \mathrm{O}_{8}+4 \mathrm{H}^{+} \rightarrow \mathrm{Na}^{+}+\mathrm{Al}^{3+}+3 \mathrm{SiO}_{2}(\mathrm{aq})+2 \mathrm{H}_{2} \mathrm{O}$ & $3.01^{\mathrm{a}}$ & 0.15 & $\begin{array}{l}1.94 \\
(0.012)^{\mathrm{c}}\end{array}$ \\
\hline K-Feldspar & $\mathrm{KAlSi}_{3} \mathrm{O}_{8}+4 \mathrm{H}^{+} \rightarrow \mathrm{K}^{+}+\mathrm{Al}^{3+}+3 \mathrm{SiO}_{2}(\mathrm{aq})+2 \mathrm{H}_{2} \mathrm{O}$ & $1.45^{\mathrm{a}}$ & 0.11 & $\begin{array}{l}1.94 \\
(0.012)^{\mathrm{c}}\end{array}$ \\
\hline Smectite & $\begin{array}{l}\mathrm{Ca}_{0.025} \mathrm{Na}_{0.1} \mathrm{Fe}(\mathrm{IIII})_{0.2} \mathrm{Fe}(\mathrm{II})_{0.5} \mathrm{~K}_{0.2} \mathrm{Al}_{1.25} \mathrm{Si}_{3.5} \mathrm{O}_{10}(\mathrm{OH})_{2}+8 \mathrm{H}^{+} \\
\rightarrow \quad 0.025 \mathrm{Ca}^{2+}+0.1 \mathrm{Na}^{+}+0.2 \mathrm{Fe}^{3+}+0.5 \mathrm{Fe}^{2+}+0.5 \mathrm{~K}^{+}+1.25 \mathrm{Al}^{3+}+ \\
1.25 \mathrm{SiO}_{2}(\mathrm{aq})+5 \mathrm{H}_{2} \mathrm{O}\end{array}$ & $\begin{aligned} & 17.57^{\mathrm{a}} \\
&+\end{aligned}$ & 0.03 & $10^{\mathrm{d}}$ \\
\hline Kaolinite & $\mathrm{Al}_{2} \mathrm{Si}_{2} \mathrm{O}_{5}(\mathrm{OH})_{4}+6 \mathrm{H}^{+} \rightarrow 2 \mathrm{Al}^{3+}+2 \mathrm{SiO}_{2}(\mathrm{aq})+5 \mathrm{H}_{2} \mathrm{O}$ & $8.55^{\mathrm{b}}$ & 0.025 & $10^{\mathrm{d}}$ \\
\hline Quartz & $\mathrm{SiO}_{2} \rightarrow \mathrm{SiO}_{2}(\mathrm{aq})$ & $-4.22^{\mathrm{a}}$ & 0.36 & $0.23^{\mathrm{e}}$ \\
\hline \multicolumn{5}{|c|}{ Model 2: Feldspar solid solution compositions } \\
\hline \multicolumn{5}{|c|}{ Model 2a: K-feldspar end-member, plagioclase solubility determined from this study } \\
\hline Plag $\left(\mathrm{An}_{30}\right)$ & $\mathrm{Na}_{0.7} \mathrm{Ca}_{0.3} \mathrm{Al}_{1.3} \mathrm{Si}_{2.7} \mathrm{O}_{8}{ }^{\mathrm{f}}$ & $8.17^{\mathrm{g}}$ & 0.15 & $\begin{array}{l}1.94 \\
(0.012)^{\mathrm{c}}\end{array}$ \\
\hline K-Feldspar & $\mathrm{KAlSi}_{3} \mathrm{O}_{8}{ }^{\mathrm{f}}$ & $1.45^{\mathrm{a}}$ & 0.11 & $\begin{array}{l}1.94 \\
(0.012)^{\mathrm{c}}\end{array}$ \\
\hline \multicolumn{5}{|c|}{ Model 2b: Literature plagioclase solid solution solubility, K-feldspar solubility determined from this study } \\
\hline Plag $\left(\mathrm{An}_{30}\right)$ & $\mathrm{Na}_{0.7} \mathrm{Ca}_{0.3} \mathrm{Al}_{1.3} \mathrm{Si}_{2.7} \mathrm{O}_{8}{ }^{\mathrm{f}}$ & $9.63^{\mathrm{h}}$ & 0.15 & $\begin{array}{l}1.94 \\
(0.012)^{\mathrm{c}}\end{array}$ \\
\hline $\mathrm{K}$-spar $\left(\mathrm{Ab}_{20}\right)$ & $\mathrm{K}_{0.8} \mathrm{Na}_{0.2} \mathrm{AlSi}_{3} \mathrm{O}_{8}{ }^{\mathrm{f}}$ & $2.63^{\mathrm{i}}$ & 0.11 & $\begin{array}{l}1.94 \\
(0.012)^{\mathrm{c}}\end{array}$ \\
\hline
\end{tabular}

${ }^{\text {a }}$ Log K value from EQ3/EQ6 database (Wolery et al., 1990)

${ }^{\mathrm{b}}$ Log K value from Yang and Steefel (2008) 
${ }^{\mathrm{c}}$ Surface area values are calculated in White et al. (2008) by applying a surface roughness factor $(\lambda)$ of 160 to the geometric estimate based on mean grain size. The first value is therefore approximately equal to a BET determination. The number in parenthesis is the calculated geometric surface area.

${ }^{\mathrm{d}}$ Surface area based on maximum bulk BET surface area in the argillic horizon of terrace 5 .

${ }^{\mathrm{e}}$ Geometric estimate.

${ }^{\mathrm{f}} \mathrm{Log} \mathrm{K}$ values are reported for reactions written in terms of $\mathrm{Al}^{3+}$ as for Model 1.

${ }^{\mathrm{g}}$ Determined this study relative to pure K-feldspar end-member of Model 1 (see text).

${ }^{\mathrm{h}} \mathrm{Log} \mathrm{K}$ value calculated from data of Arnorsson \& Stefansson (1999)

${ }^{\mathrm{i}}$ Determined this study relative to Plag(An30) log K calculated from Steffanson \& Arnorsson (1999). For reference, $\log \mathrm{K}$ values for $\mathrm{Ab}_{20}$ reported by Arnorsson \& Stefansson (1999) range from 1.07 to 5.50. 
Table 2: Initial conditions and boundary conditions used in SCT 5 (226 ka) simulations, values are measured precipitation corrected for evapotranspiration to reflect shallow soil water.

\begin{tabular}{lc}
\hline & $\begin{array}{c}\text { Boundary } \\
\text { Conditions }\end{array}$ \\
\hline $\mathrm{Temp} .\left({ }^{\circ} \mathrm{C}\right)$ & 12 \\
$\mathrm{pH}$ & 5.13 \\
$\mathrm{CO}_{2}(\mathrm{~g})$ (bars) & $0.01^{\mathrm{a}}$ \\
& $\begin{array}{c}\text { Conc. (mol/kg) } \\
\mathrm{SiO}_{2(\mathrm{aq})}\end{array}$ \\
$\mathrm{Al}^{3+}$ & $2.0 \times 10^{-7}$ \\
$\mathrm{Ca}^{2+}$ & $2.0 \times 10^{-7}$ \\
$\mathrm{~K}^{+}$ & $9.0 \times 10^{-5}$ \\
$\mathrm{Mg}^{2+}$ & $1.6 \times 10^{-5}$ \\
$\mathrm{Na}^{+}$ & $6.8 \times 10^{-5}$ \\
$\mathrm{Fe}^{3+}$ & $4.2 \times 10^{-4}$ \\
$\mathrm{Sr}^{2+}$ & $1.0 \times 10^{-7}$ \\
$\mathrm{Cl}^{+}$ & $5.1 \times 10^{-7}$ \\
$\mathrm{NO}_{3}^{-}$ & $4.6 \times 10^{-4}$ \\
$\mathrm{SO}_{4}^{2-}$ & $1.0 \times 10^{-4}$ \\
\hline
\end{tabular}

${ }^{\mathrm{a}}$ fixed in soil profile based on measured soil gas concentrations. 
Table 3: Mineral specific selectivities and cation exchange capacities (CEC) calculated from a fit to cation exchange data. Data are shown for a fit to the pooled data for exchangeable, pore water and mineral volumes for SCT1, SCT2, SCT3 and SCT5.

\begin{tabular}{lc}
\multicolumn{1}{c}{ Mineral } & \multicolumn{1}{c}{ Selectivities } \\
\hline Kaolinite & \\
$\mathrm{K}^{+} / \mathrm{Mg}^{2+}$ & $-1.18 \pm 0.11$ \\
$\mathrm{Na}^{+} / \mathrm{Mg}^{2+}$ & $0.30 \pm 0.25$ \\
$\mathrm{Ca}^{2+} / \mathrm{Mg}^{2+}$ & $-0.02 \pm 0.06$ \\
$\mathrm{Sr}^{2+} / \mathrm{Mg}^{2+}$ & $-0.06 \pm 0.48$ \\
$\mathrm{Smectite}^{2+}$ & \\
$\mathrm{K}^{+} / \mathrm{Mg}^{2+}$ & $-1.46 \pm 0.23$ \\
$\mathrm{Na}^{+} / \mathrm{Mg}^{2+}$ & $-0.35 \pm 0.32$ \\
$\mathrm{Ca}^{2+} / \mathrm{Mg}^{2+}$ & $-0.15 \pm 0.16$ \\
$\mathrm{Sr}^{2+} / \mathrm{Mg}^{2+}$ & $-0.25 \pm 1.13$ \\
$\mathrm{CEC} \mathrm{Smectite}^{\mathrm{a}}$ & $86.1 \pm 5.4$ \\
$\mathrm{CEC} \mathrm{Kaolinite}^{\mathrm{a}}$ & $9.4 \pm 1.8$ \\
\hline${ }^{\mathrm{a}} \mathrm{CEC}$ in meq &
\end{tabular}


Table 4: Summary of rate constants for Santa Cruz, terrace 5 compared to laboratory rate constants. Uncertainties are based on reverse parameter estimation using PEST and include the effects of uncertainty in the flow rate (See Appendix 1.3)

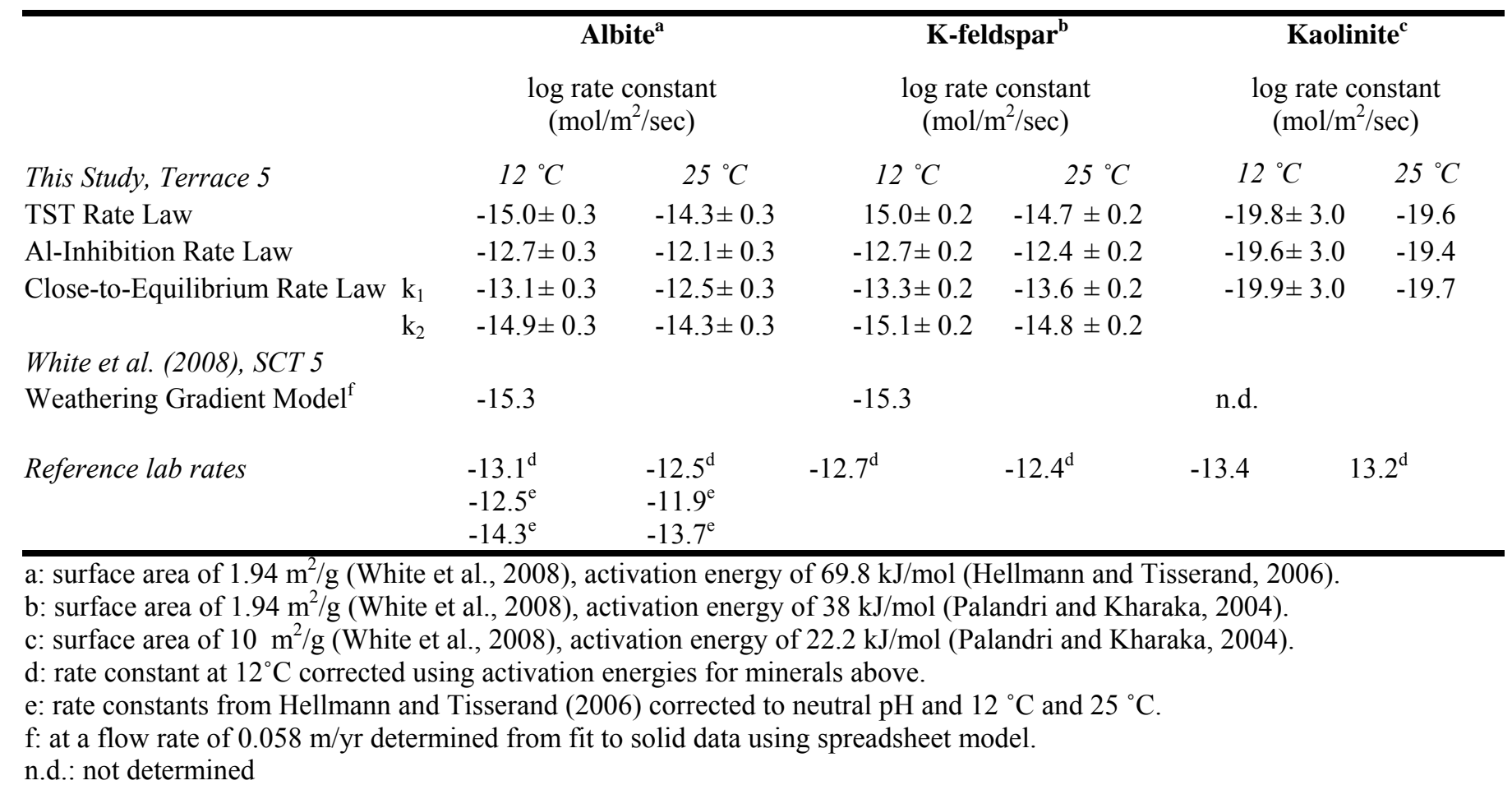


Table 5: Correlation coefficients for the individual rate mineral rate constants and the flow rate from a fit to data using a reverse parameter estimation program, PEST (Doherty et al., 2004) in conjunction with CrunchFlow.

\begin{tabular}{c|cccc} 
& K-feldspar & Plagioclase & Kaolinite & Flow Rate \\
\hline K-feldspar & 1.00 & -0.41 & 0.25 & -0.15 \\
Albite & -0.41 & 1.00 & -0.18 & 0.04 \\
Kaolinite & 0.25 & -0.18 & 1.00 & -0.94 \\
Flow Rate & -0.15 & 0.04 & -0.94 & 1.00
\end{tabular}




\section{FIGURE CAPTIONS:}

Figure 1. Location of Santa Cruz, CA marine terraces (see White et al. (2008) for more detailed site map). Terrace $5(226 \mathrm{ka})$ is the primary focus of this study. Other terrace ages are $65 \mathrm{ka}$, (SCT 1), $90 \mathrm{ka}$ (SCT 2), $137 \mathrm{ka}$ (SCT 3).

Figure 2. Profile evolution between SCT 1 (65 ka) and SCT 5 (226 ka). The zone of peak kaolinite accumulation referred to as the argillic horizon is shown as thick dashed lines, and the average water table depth is shown as a light stippled line. Quartz abundance not shown. Data summarized from White et al. (2008).

Figure 3. Summary of cation exchange data and comparison of calculated exchangeable values and measured values for the selectivities determined by a fit to the pooled data from four terraces. The volumes of smectite and kaolinite, the measured bulk exchangeable fractions and the measured pore water values were used to determine the mineral specific cation exchange capacity (CEC) and selectivities (Table 3).

Figure 4: Base case model profiles corresponding to the SCT 5 (226 ka) profile determined using the linear TST model (L-TST). Profiles corresponding to the ages of the younger terraces are shown for reference and the SCT 5 profile is shown in bold. A$\mathrm{C}$ : Profile evolution for K-feldspar and albite dissolution and kaolinite precipitation. D$\mathrm{E}$ : overall reaction rates $(\mathrm{mol} / \mathrm{L}$ (porous media)/sec) as a function of depth for individual minerals.

Figure 5. Saturation state profiles from model simulations compared to values calculated from aqueous concentrations.

Figure 6: A-B) Fit to solid major element data (wt. \% oxide) for models $2 \mathrm{a}$ and $2 \mathrm{~b}$ respectively using the reactions and $\log \mathrm{K}$ values from Table 1. (Fit to mineral abundance profiles is approximately the same as in Fig. 4); C-D) model and measured saturation state for above models $2 \mathrm{a}$ and $2 \mathrm{~b}$ calculated using the same $\log \mathrm{K}$ values given in Table 1 (* denotes model fit of $\log \mathrm{K}$ value).

Figure 7. Comparison between measured aqueous concentrations and model values from the best fit to the data using the TST model. A) model $\mathrm{pH}$ is shown relative to the calculated $\mathrm{pH}$ based on pore water alkalinity and measured $\mathrm{PCO}_{2}, \mathrm{~B}-\mathrm{C}$ ) measured and model-predicted $\mathrm{SiO}_{2}(\mathrm{aq})$ and $\mathrm{Al}$ concentrations, D-F) net pore water solute concentrations from weathering as calculated in White et al. (2008), compared to model values corrected for precipitation inputs. Note that in $(F)$ the calculated weatheringderived $\mathrm{K}^{+}$results in a negative value.

Figure 8. Results from mineral-specific cation exchange simulations. A) Comparison of model and measured smectite and kaolinite abundances for SCT 5; B) total model CEC during profile evolution compared to final and measured CEC at SCT 5. C) Comparison of CEC partitioning between smectite and kaolinite. 
Figure 9. Comparison of the different rate law formulations as a function of saturation state. The range of values corresponding to the observed saturation state at the peak of the albite reaction front profile (e.g. 3 to 4 meters). The effect of Al-inhibition could not be shown, but it can be assumed that the inhibition effect is similar in magnitude to the ratio of the L-TST to the AIM $(\mathrm{m}=1 / 3)$ profile. The model rates are all within a similar range within the field of observed saturation state values.

Figure 10. Effect of variations in the flow rate on model profiles. The value determined from the chloride mass balance approach $(0.088 \mathrm{~m} / \mathrm{yr})$ is shown in bold. All rate constants are from the best fit to the data using the L-TST model.

Figure 11. Effect of a factor of 5 variation in the kaolinite precipitation rate (relative to best-fit value) on the primary mineral profiles A) kaolinite profile; B) albite; C) Kfeldspar, also shown for reference is the weathering profile in the absence of kaolinite precipitation. Albite and K-spar rate constants are from Table 4.

Figure 12: Aluminum inhibition model shown at $\mathrm{pH} 6$ as a function of total $\mathrm{Al}$ concentration. Open circle shows value calculated for representative Al concentrations at Santa Cruz. Also shown are the rates corresponding to total Al concentrations for kaolinite equilibrium at variable $\mathrm{SiO}_{2}$ (aq) concentrations.

Figure 13: Albite and kaolinite saturations $(\log I A P / K)$ showing the measured and model values and the undersaturation of albite at supersaturation of kaolinite for the Santa Cruz pore waters.

Figure 14: Simulation of the effect of eolian input $\left(21.5 \mathrm{~g} / \mathrm{m}^{2} / \mathrm{yr}\right)$ to the top of the profile continuously over $226 \mathrm{ka}$. All rates are as in Fig. 4 using the L-TST model. The protolith mineral abundances were used to reflect the eolian composition assuming a local source area.

Figure 15: Effect of variations in model soil $P \mathrm{CO}_{2}$ on model profiles and calculate values for L-TST model. In order to fit the solid profile data under different $P \mathrm{CO}_{2}$ concentrations required changes in the kaolinite precipitation rate but did not affect the calculated primary mineral dissolution rate constants.

Figure 16: Effect of variations in the initial abundance of kaolinite in the model: A,B) effect of variations in the $\log \mathrm{K}$ of kaolinite of approximately one order of magnitude; best fit is from Yang and Steefel (2008), less soluble value is from EQ3/EQ6 database (Wolery et al., 1990). C, D) as the initial mineral volume abundance is increased the overall rate and amount of kaolinite precipitation increases and results in more weathering of albite. 
Figure 1

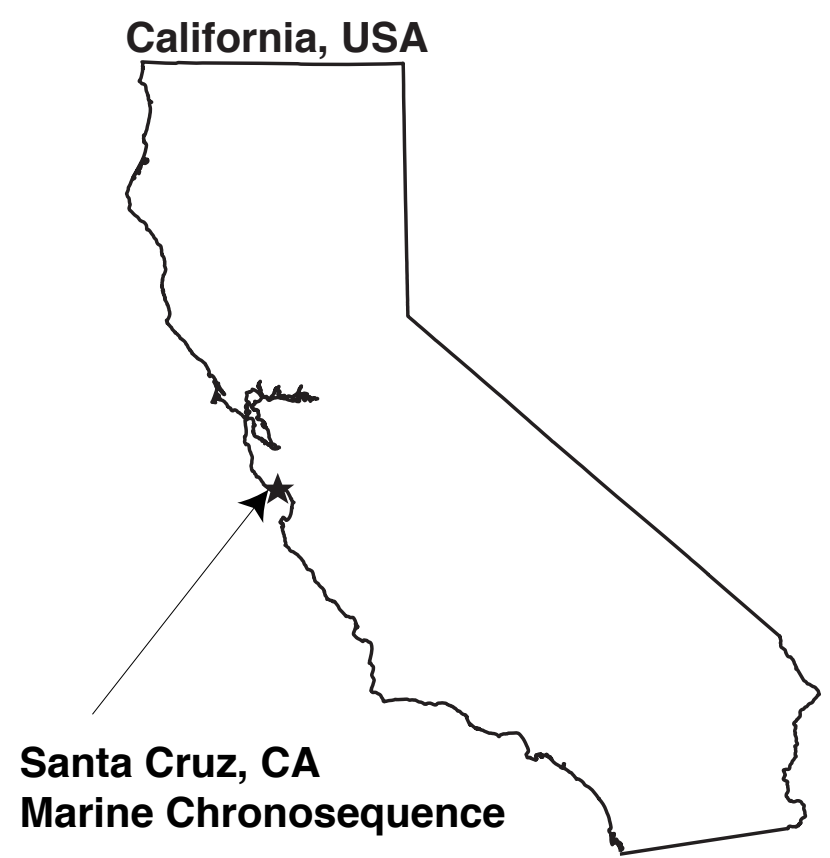


Figure 2
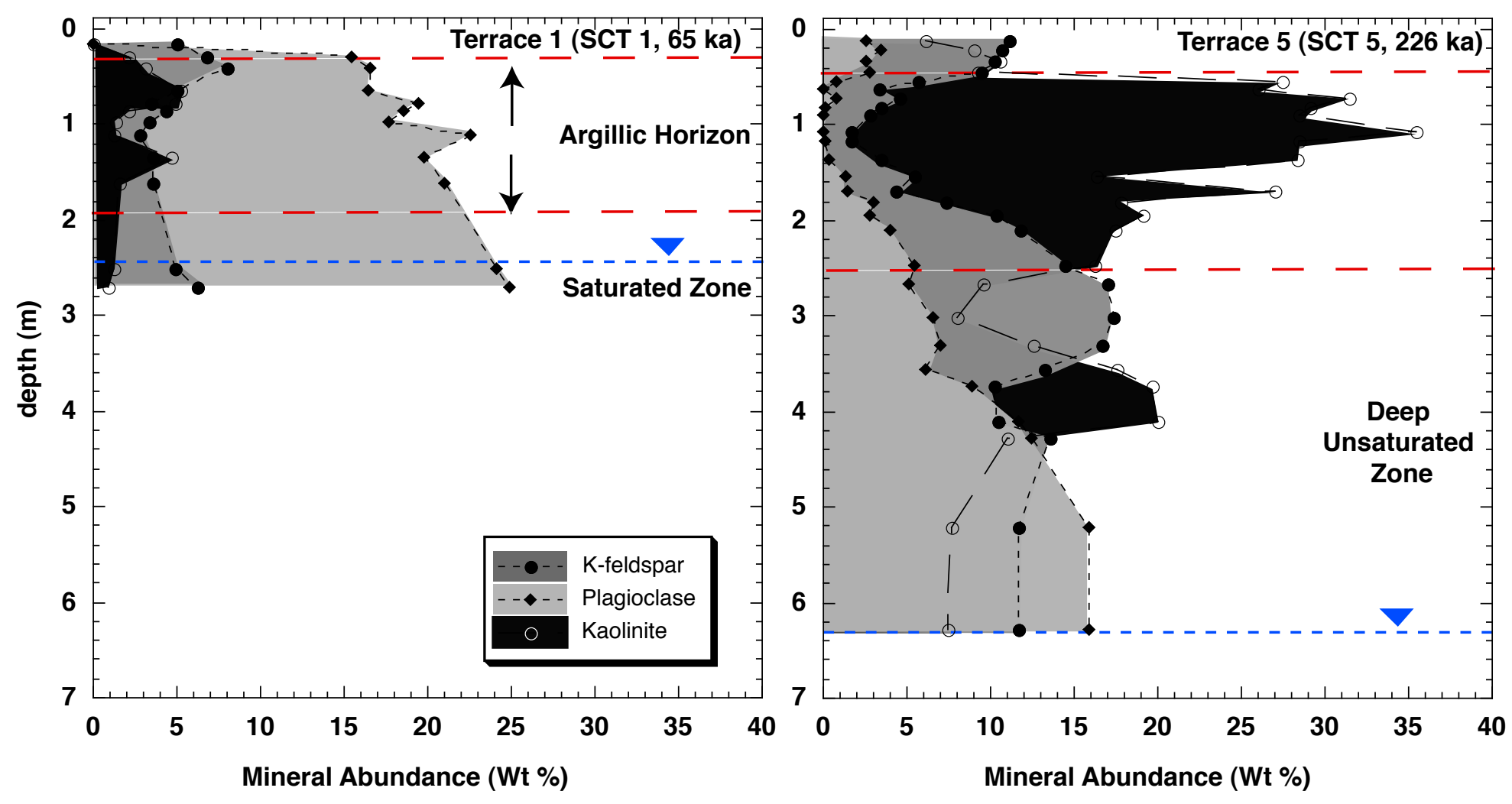
Figure 3

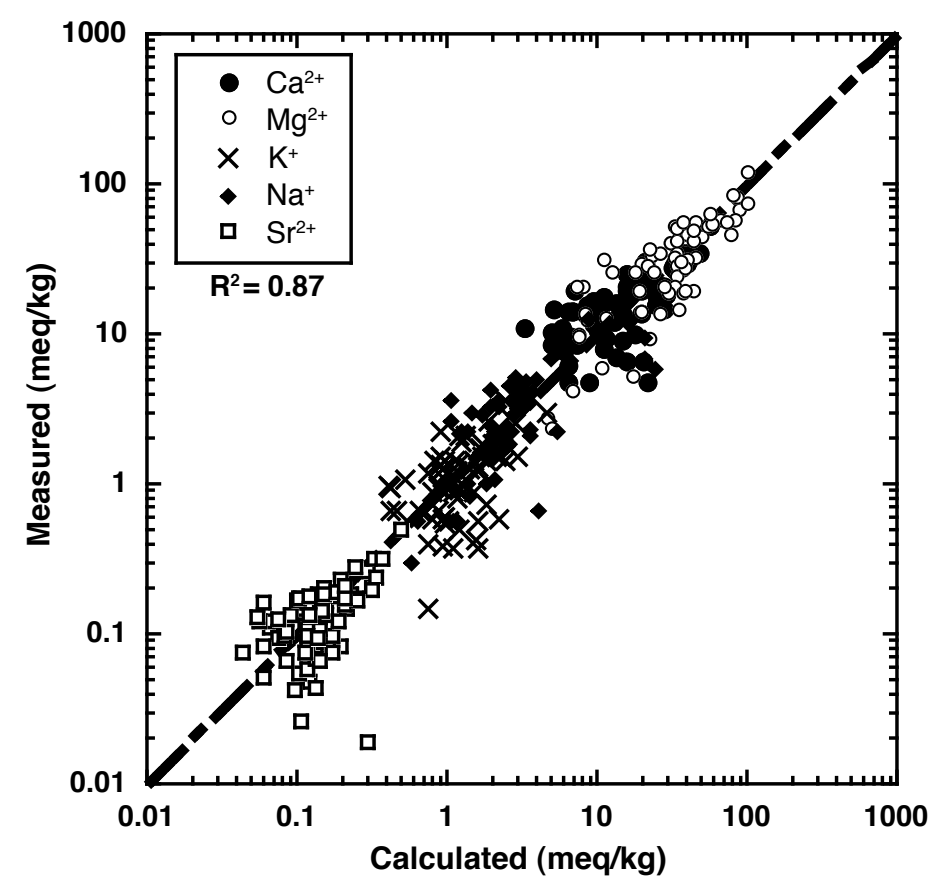



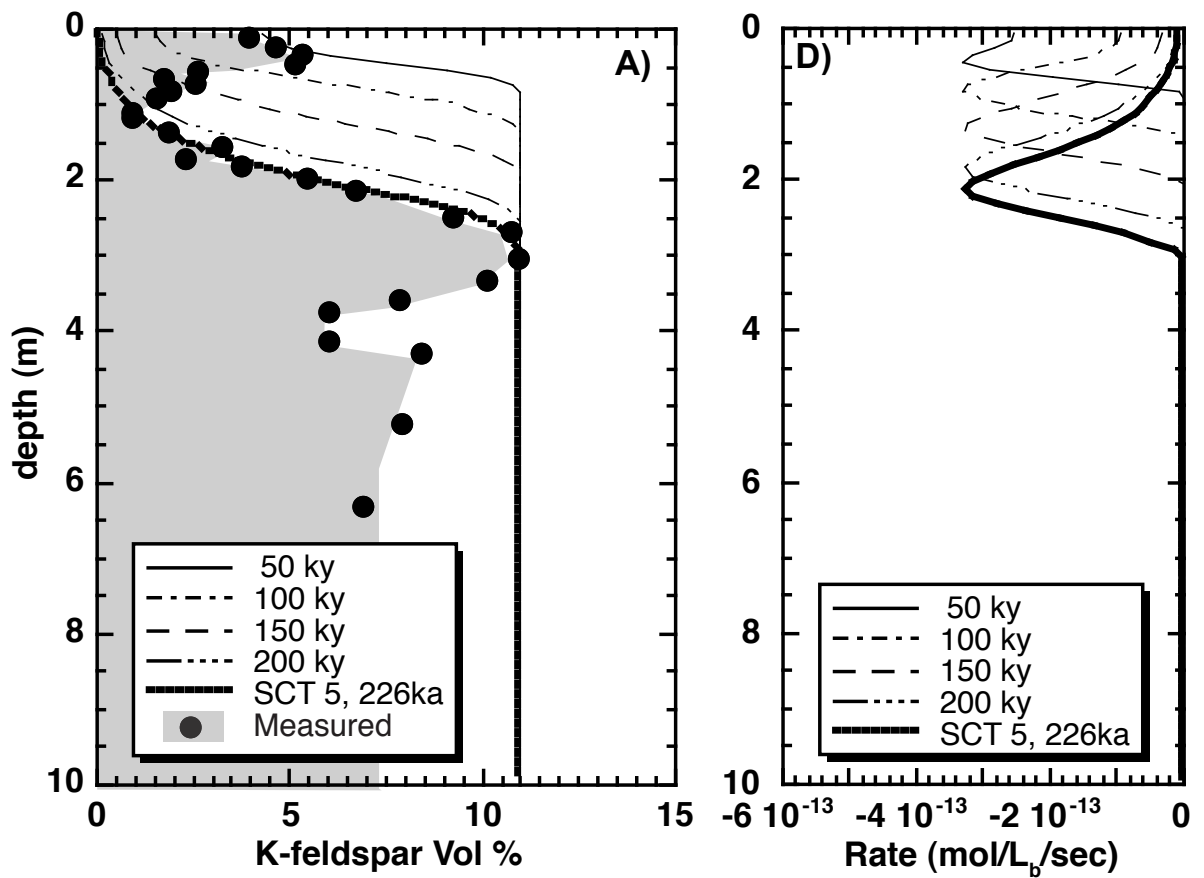

Figure 4
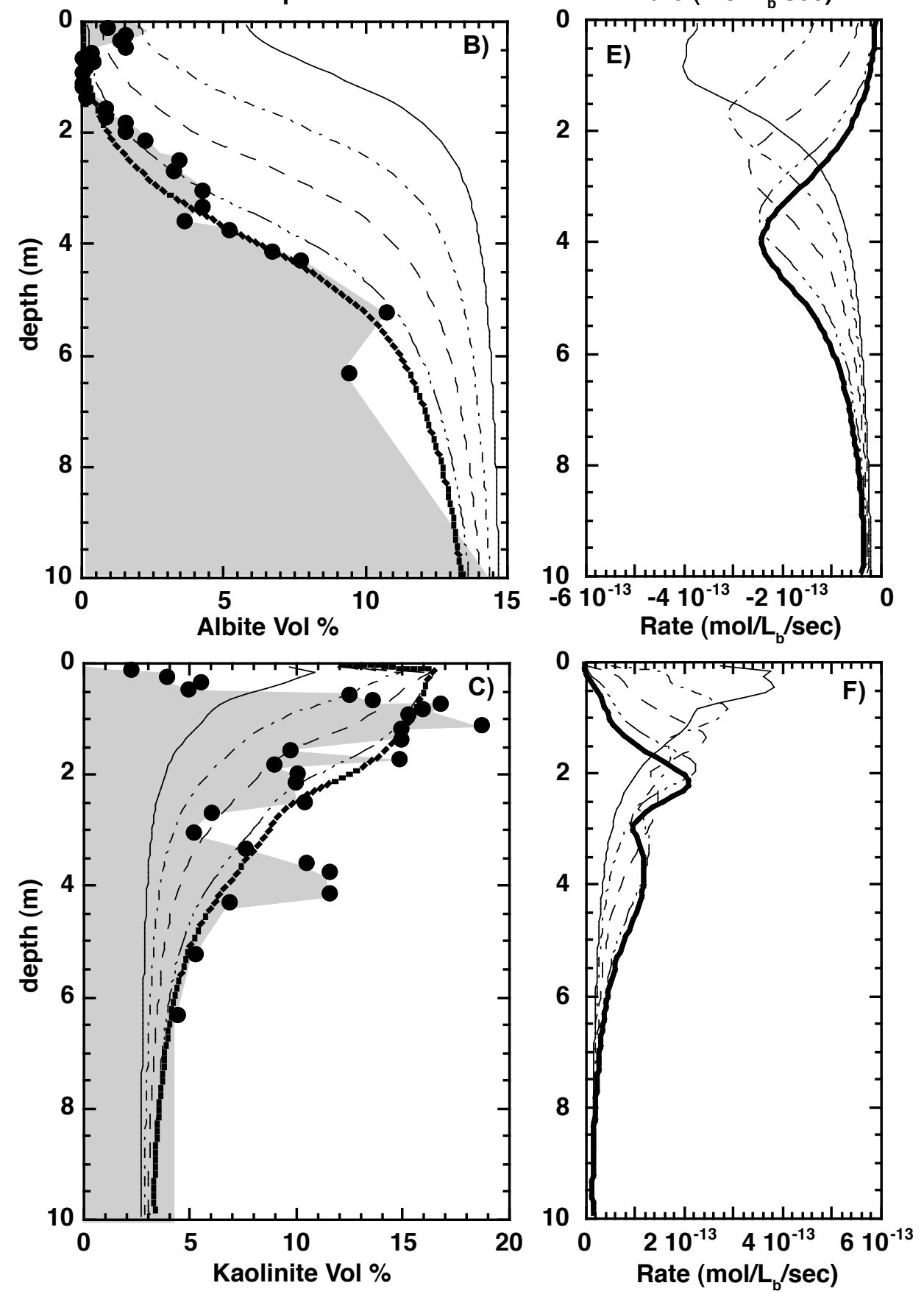
Figure 5. Temporal evolution of saturation state
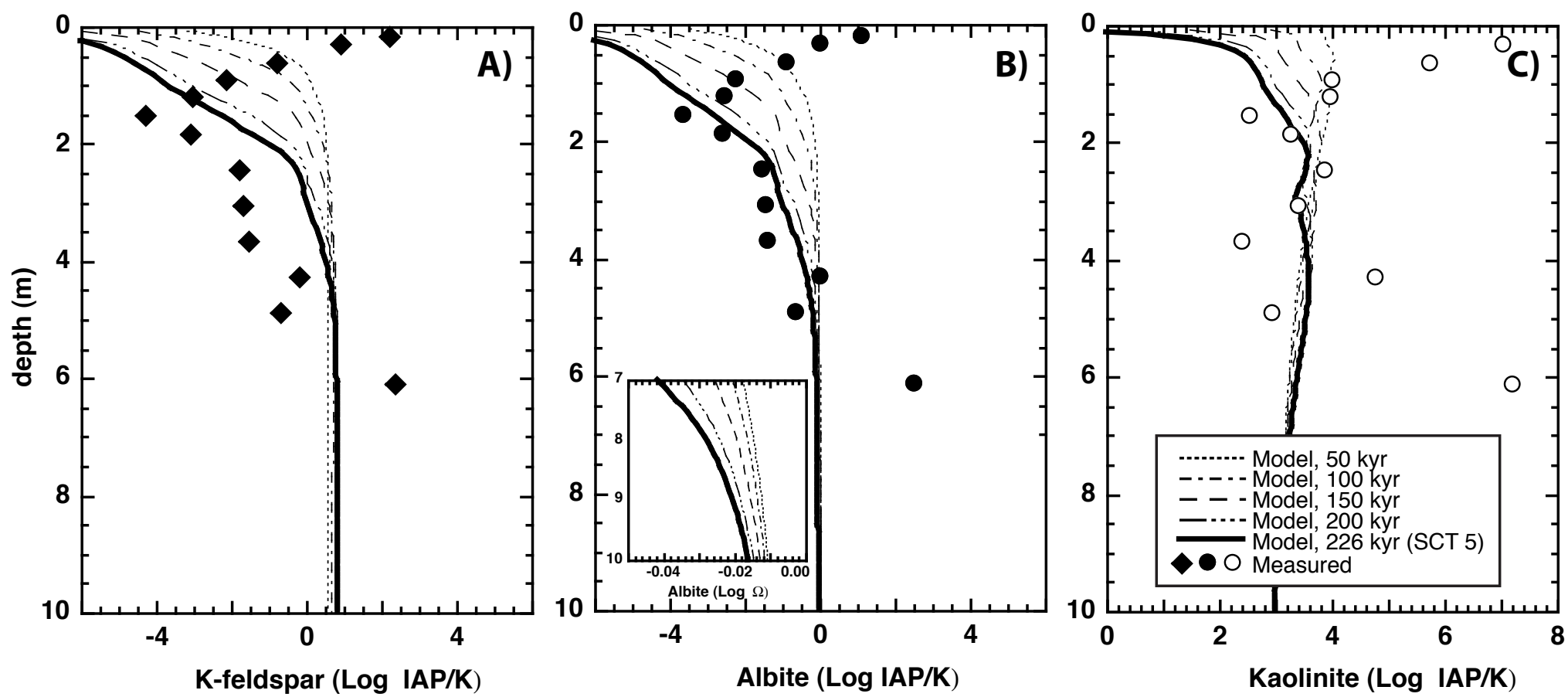
Figure 6
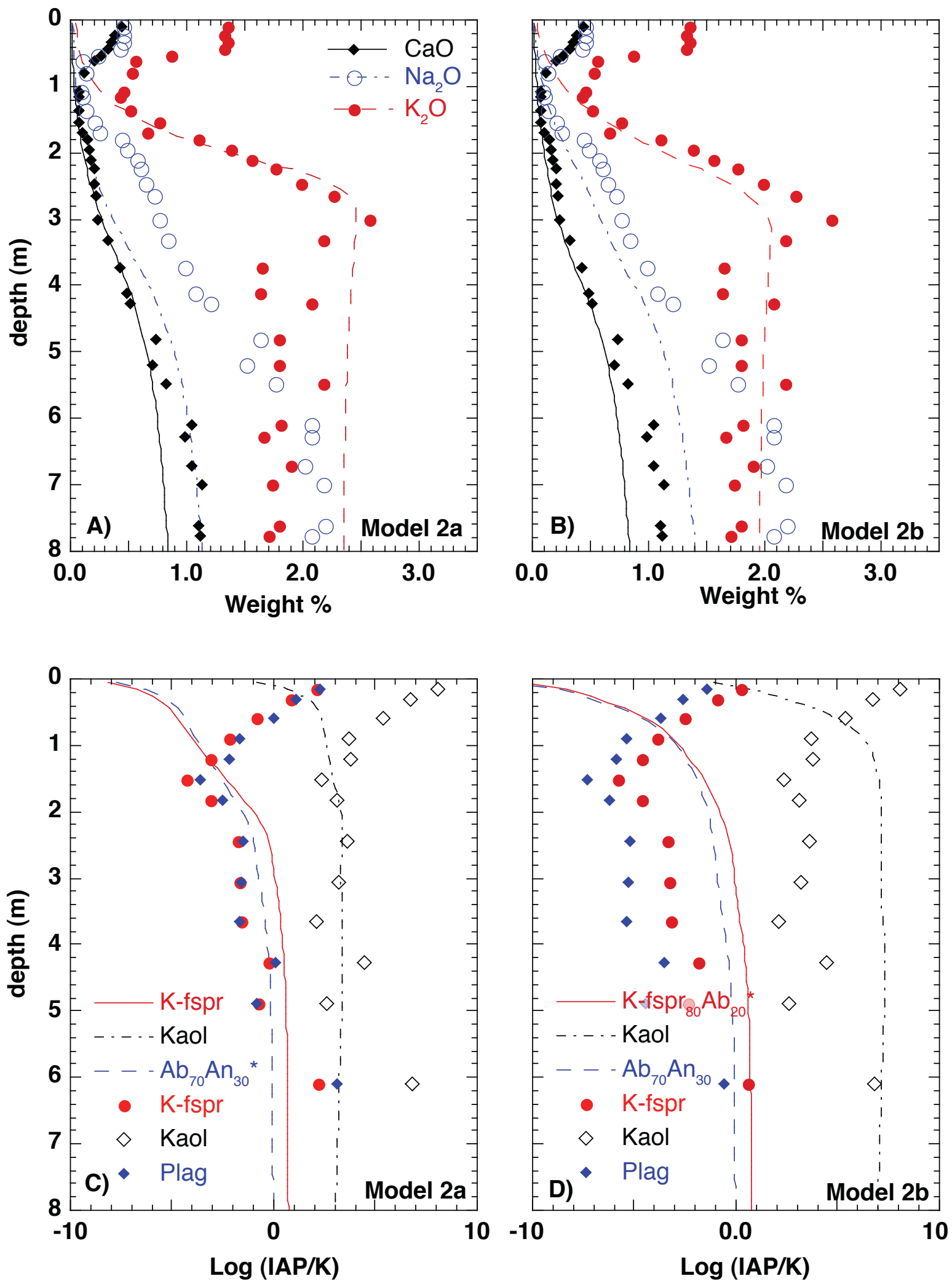
Figure 7
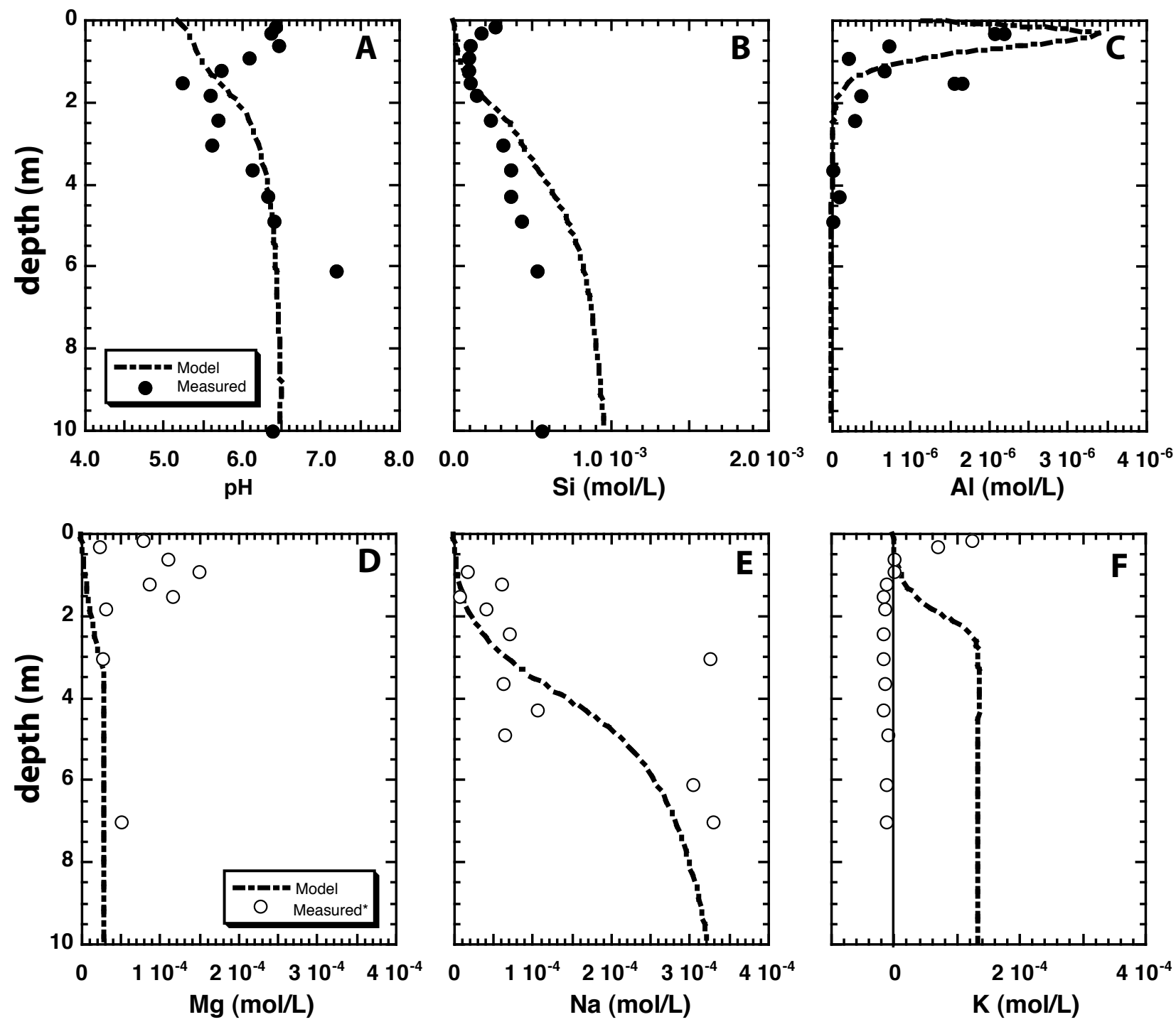

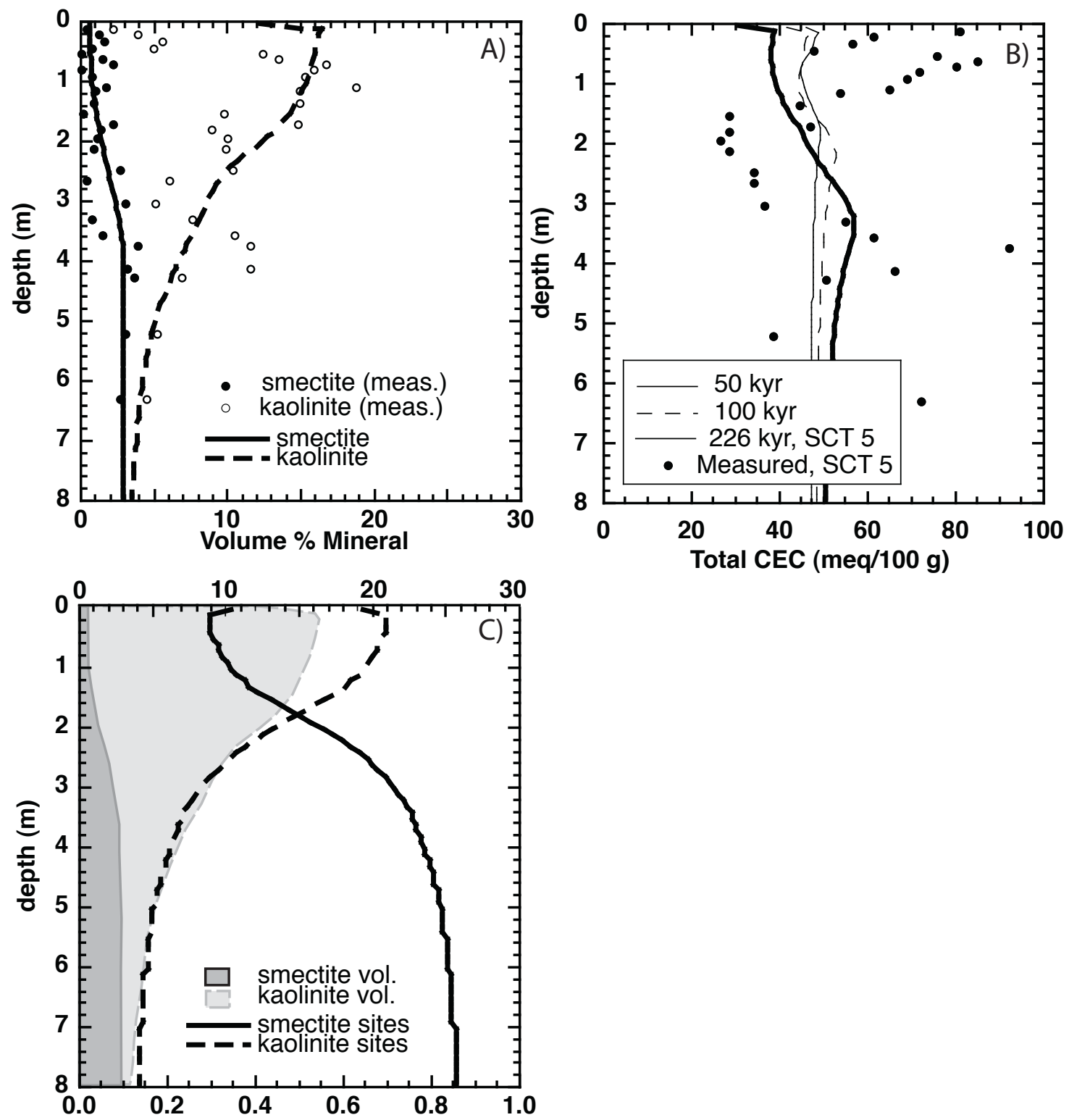

Fraction of Total Exchangeable 
Figure 9

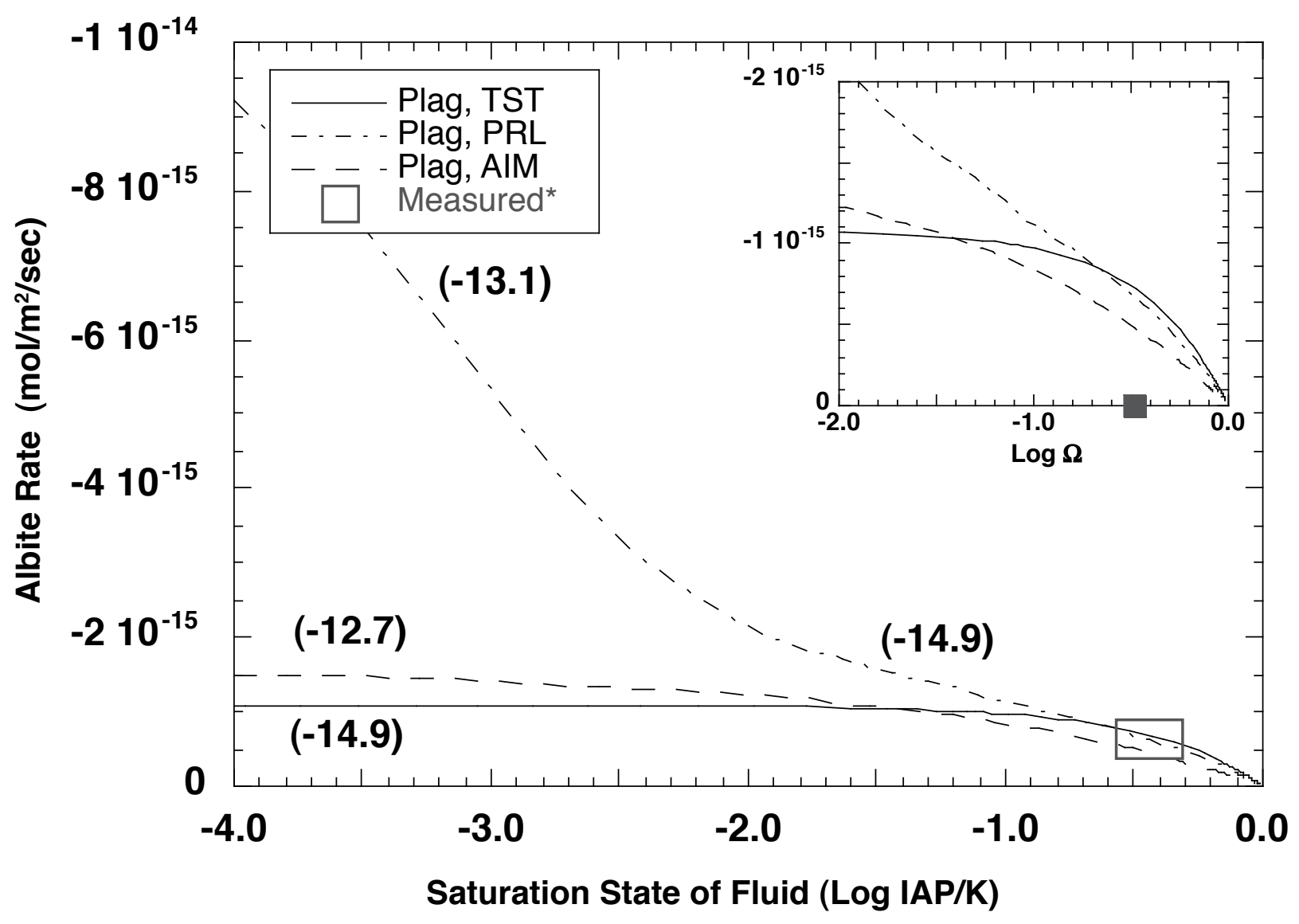


Figure 10
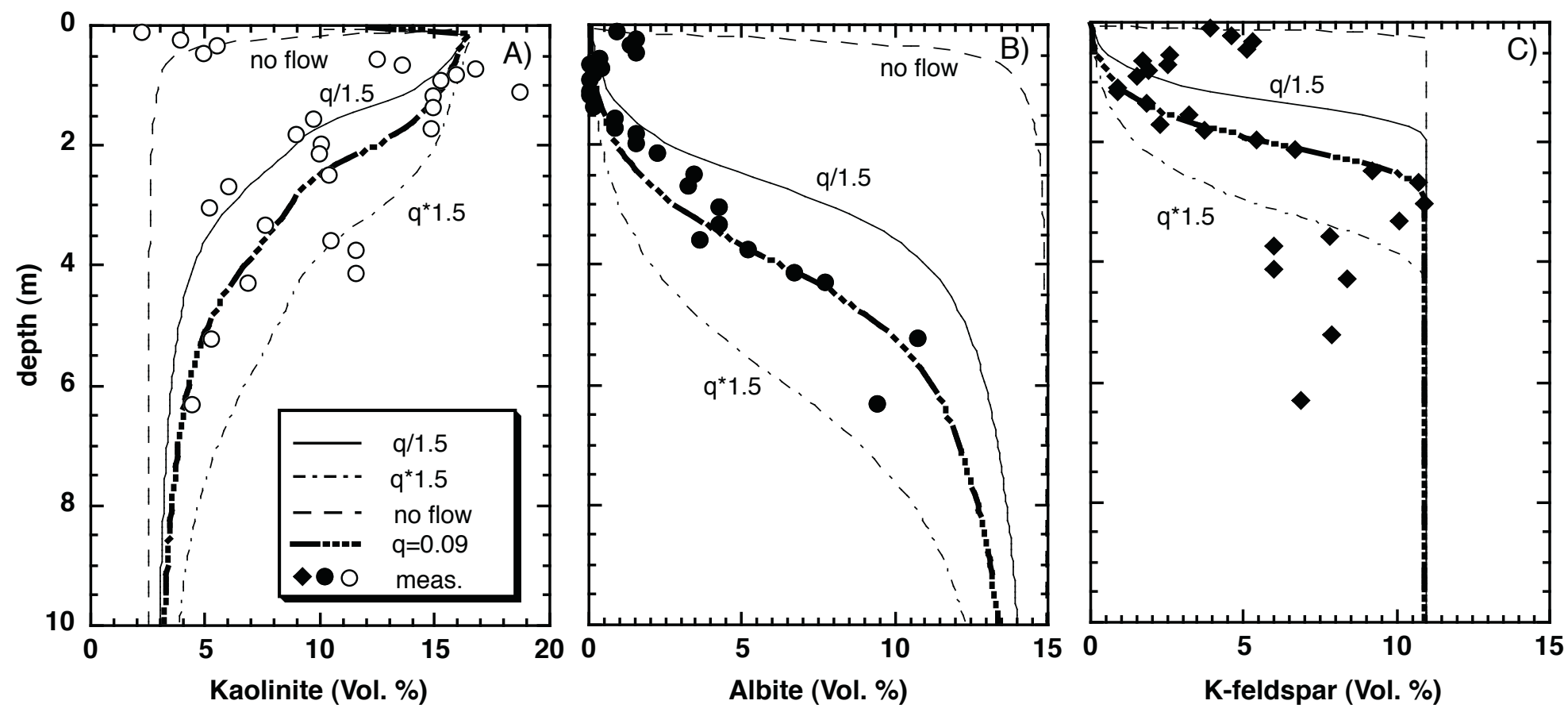
Figure 11
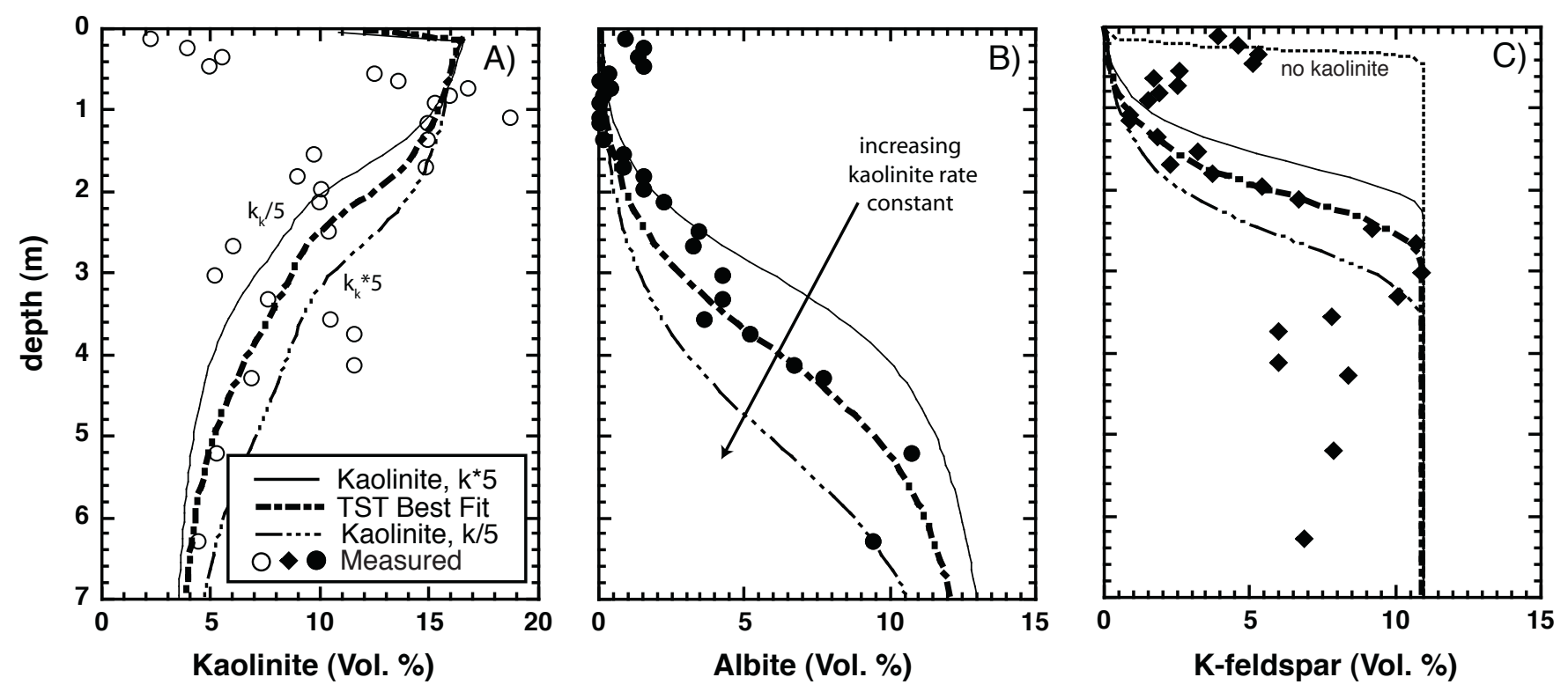
Figure 12

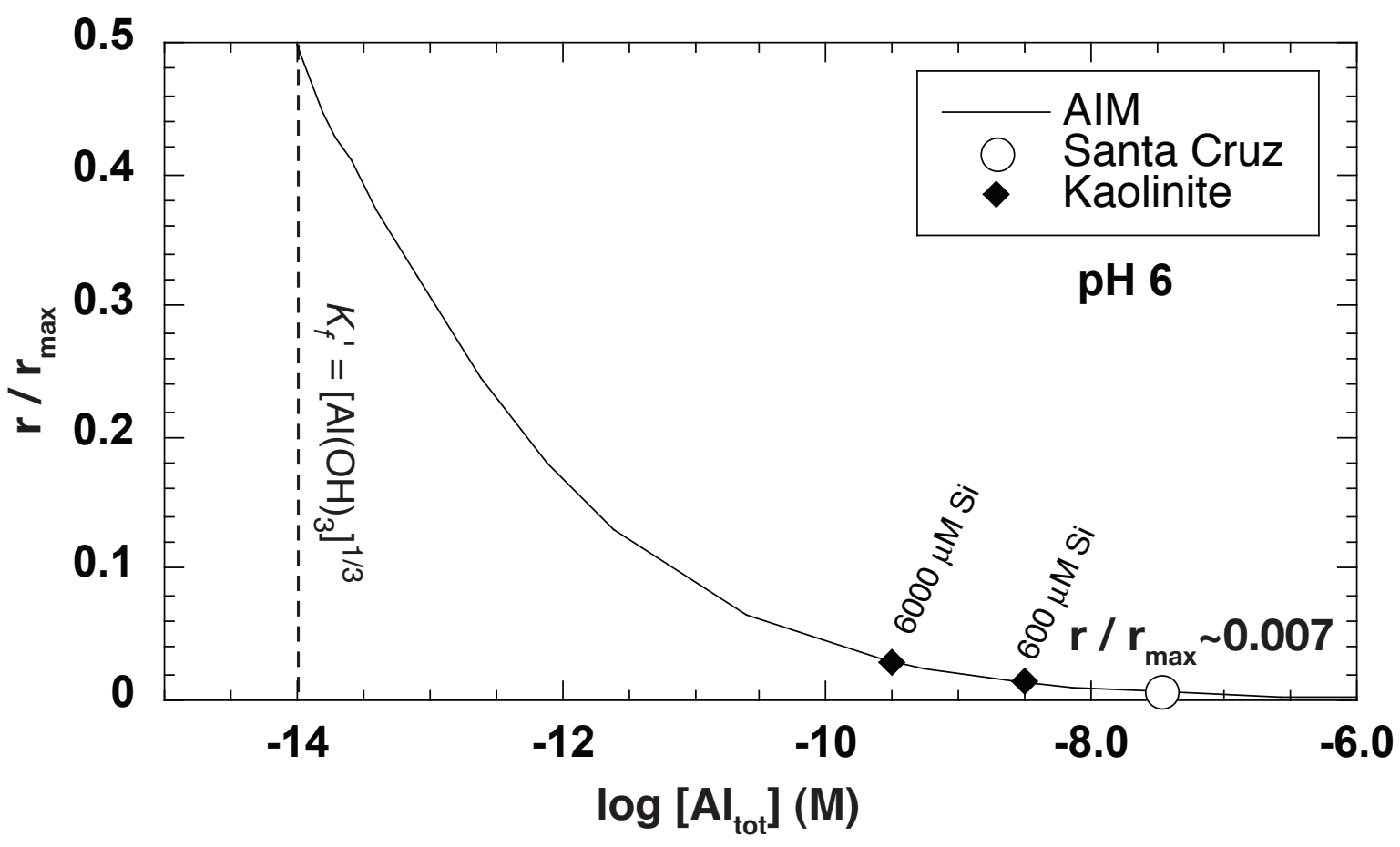


Figure 13

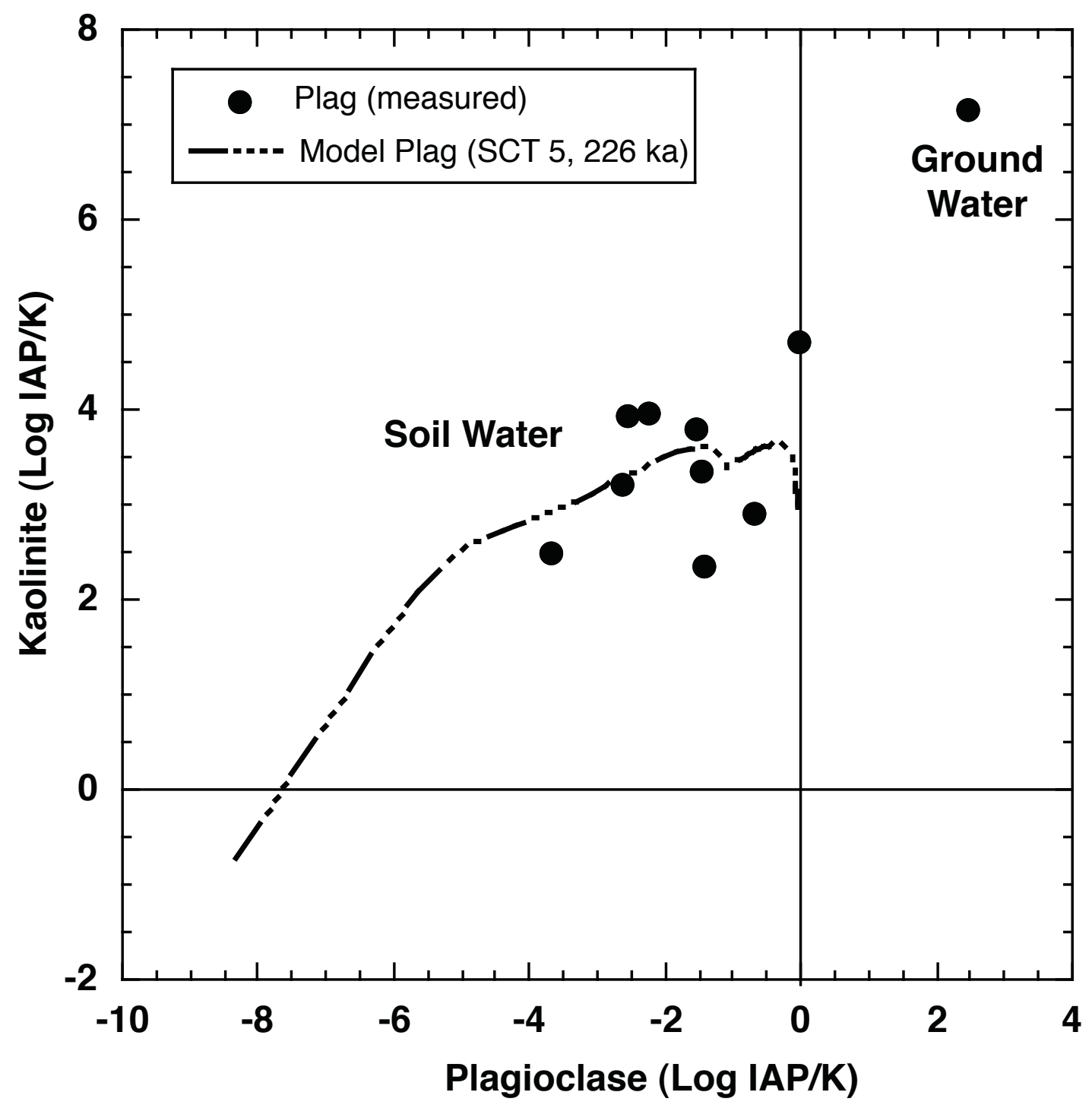


Figure 14

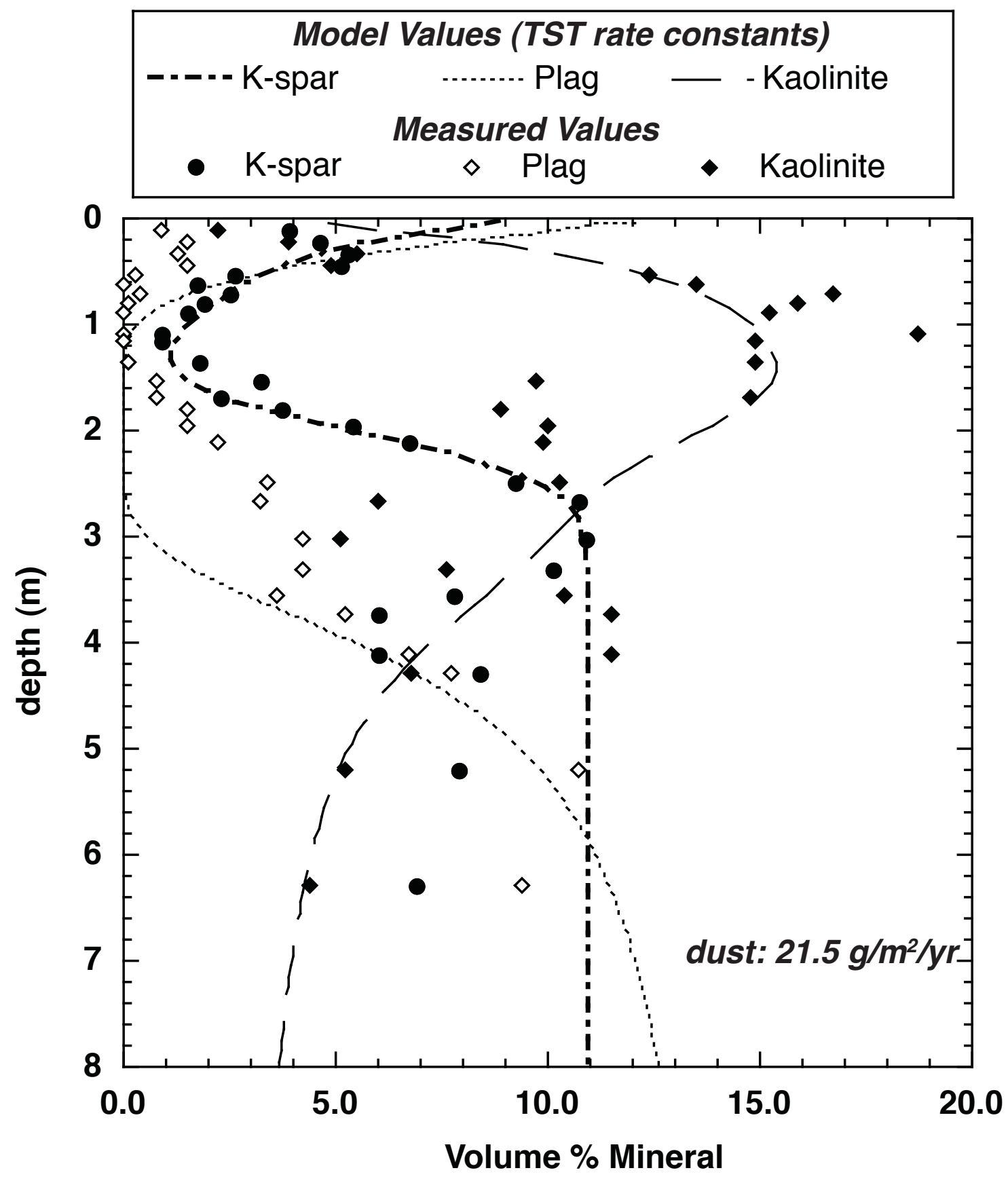


Figure 15

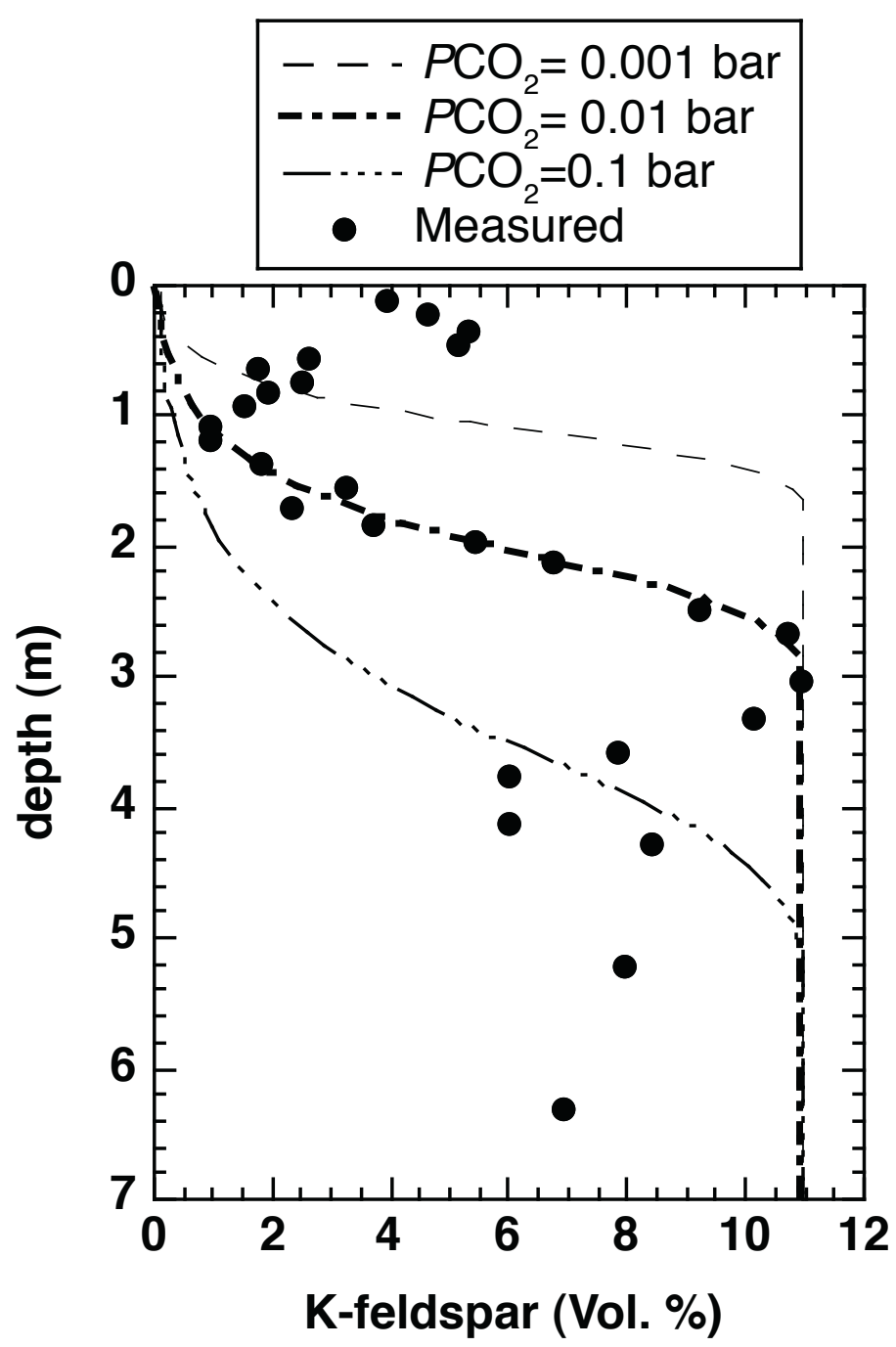


Figure 16
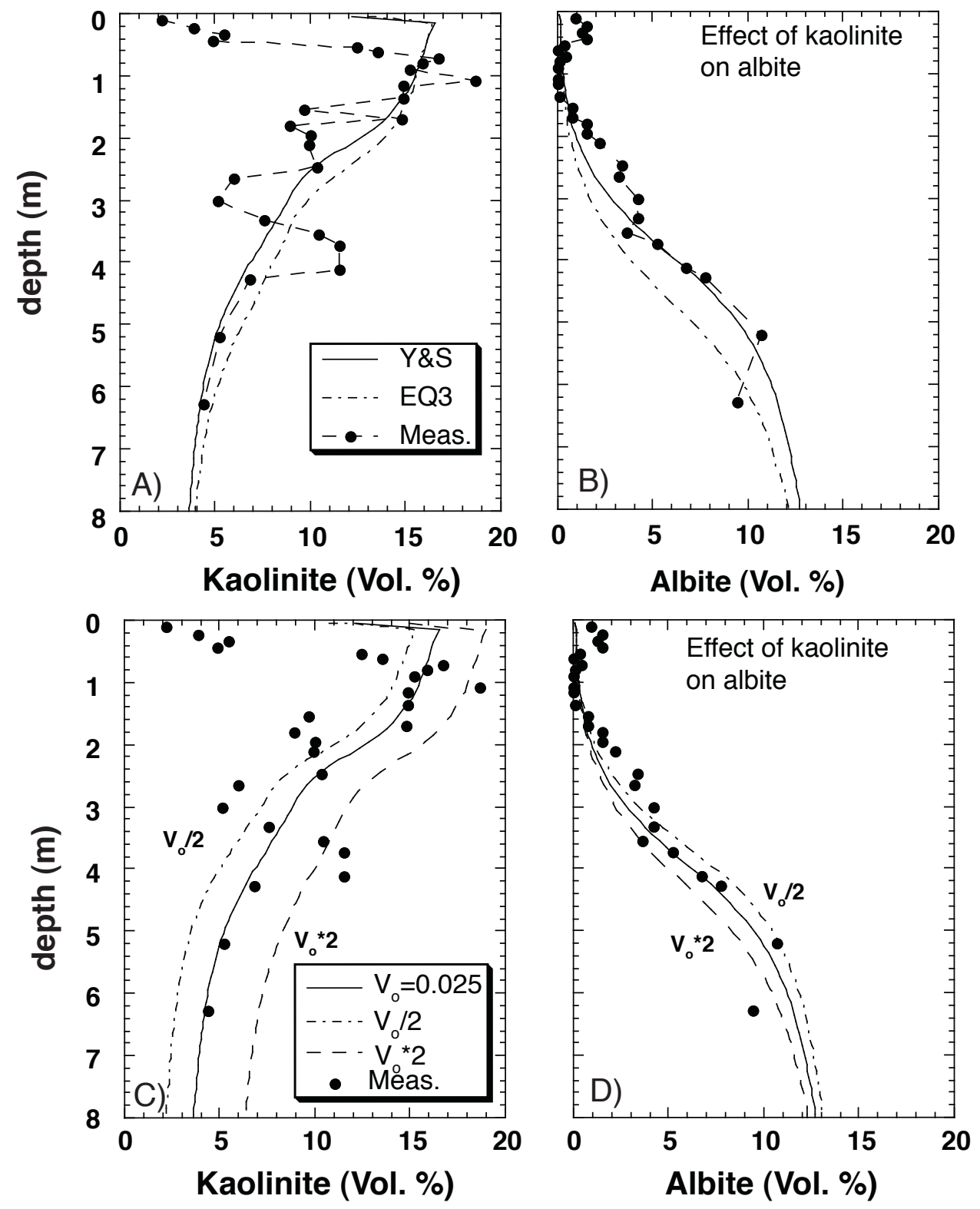